\title{
Changes in crop type distribution in Zhangye City of the Heihe River Basin, China
}

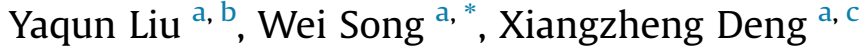 \\ ${ }^{a}$ Key Laboratory of Land Surface Pattern and Simulation, Institute of Geographic Sciences and Natural Resources Research, Chinese Academy of Sciences, \\ Beijing 100101, PR China \\ ${ }^{\mathrm{b}}$ College of Architecture and Urban Planning, Chongqing Jiaotong University, Chongqing 400074, PR China \\ ${ }^{\mathrm{c}}$ Center for Chinese Agricultural Policy, Chinese Academy of Sciences, Beijing 100101, PR China
}

\section{A R T I C L E I N F O}

\section{Article history:}

Received 10 December 2015

Received in revised form

5 September 2016

Accepted 11 September 2016

Available online 17 September 2016

\section{Keywords:}

Crop type distribution

Multi-temporal TM/ETM+ images

Decision tree

Landscape pattern

Crop conversion potentials

The Heihe River Basin

\begin{abstract}
A B S T R A C T
With rapid economic development in China, crops have undergone remarkable changes in both their type and spatial pattern. Timely and accurate information of crop type distribution will help government and agricultural producers quickly understand regional agricultural production conditions to better facilitate appropriate adjustments in planting patterns and policies. Another benefit of acquiring such knowledge of crops is that it should enhance regional agricultural competitiveness, optimize resource allocations, and further guarantee national food security. Towards this end, and using the Zhangye City in the Heihe River Basin as a study area, the present research elaborated upon a methodology to classify crop type distribution based on multi-temporal Thematic Mapper and Enhanced Thematic Mapper Plus (TM/ETM+) images. Using this methodology we achieved the spatial distributions of crop types in Zhangye City in 2007 and 2012, and analyzed changes in their distributions over this period. In addition, some landscape indices were calculated to clarify the landscape pattern of crops. The crop conversion potentials in 2017 were modeled using four conversion sub-models of the Multi-Layer Perceptron (MLP) neural network. Generally, the overall accuracy of crop classification in Zhangye was high, at 89.38\%. From 2007 to 2012, the cultivated land area in Zhangye increased from $463.81 \times 10^{3}$ ha to $493.89 \times 10^{3}$ ha. The sowing area of corn and oilseed rape increased by $39.21 \times 10^{3}$ ha and $5.99 \times 10^{3}$ ha, respectively, while for wheat and barley the sowing area decreased by $3.61 \times 10^{3}$ ha and $9.14 \times 10^{3}$ ha, respectively. Considering other crop types as a group, their sowing area decreased by only $2.37 \times 10^{3}$ ha. The increase in corn sowing area mainly came from the conversion of other crops to corn, which accounted for $43.09 \%$ of its total sowing area in 2012. Furthermore, corn and oilseed rape showed a tendency of intensive sowing, whereas for wheat and barley the tendency was towards scattered sowing. For the future, corn has high conversion potential in Linze and Gaotai counties of Zhangye, while wheat, barley and oilseed rape have high conversion potentials in Minle and Shandan counties.
\end{abstract}

(C) 2016 Elsevier Ltd. All rights reserved.

\section{Introduction}

China has rapidly transformed from a centrally planned economy to one that is market-oriented since the reform and openingup policies were brought forth in 1978. In carrying out these reforms, the traditional mode of self-supportive agricultural production has been commoditized alongside the implementation of the "household responsibility system" (Chen, Wang, Fu, \& Qiu, 2001; Lin \& Ho, 2003; Song, Chen, \& Zhang, 2013). Changes in

\footnotetext{
* Corresponding author.

E-mail address: songw@igsnrr.ac.cn (W. Song).
}

climate, economics, urbanization, and the rural labor force have jointly driven significant adjustments in crop type distributions in China (Liu \& Tian, 2010; Song \& Liu, 2014; Xu et al., 2014; Yang, Feng, Huang, \& Lin, 2008). A key example is the sowing proportion of China's cash crops, namely vegetables, melons, and fruits, which is growing rapidly whereas that of grain crops shows the opposite trend (Tong, Hall, \& Wang, 2003; Verburg, Chen, \& Veldkamp, 2000; Wu \& Li, 2012). Considered in a broad spatial context, the traditional sowing center of China's grain crops has moved northward and eastward (Xu et al., 2013; You, Spoor, Ulimwengu \&Zhang, 2011). Changes in crop type distribution can directly influence the economic benefits of farmers, agricultural water consumption, and food security in China (Basche et al., 2016; 
Deng, Huang, Rozelle, \& Uchida, 2006; Ye et al., 2015). For instance, substituting grain crops with economic crops will increase the economic benefits to farmers, but it would be surprising if it did not also influence food security. Therefore, in order to better understand the absolute and relative patterns of food production, and to guarantee the long-term food security of China, it is now necessary to obtain accurate information concerning its crop type distributions and their spatial-temporal changes.

The traditional means of acquiring crop type distribution information relies on statistical data released by the National Bureau of Statistics of China. However, such data is generally aggregated using county as the statistical unit, which precludes spatial information of crop type distributions at the smaller scale of plot. Without this finer resolution, it will remain hard to carry out further research via coupling with other spatial data; e.g., the evaluation of the crops' water use efficiency via coupling with local evapotranspiration data (Johnson \& Trout, 2012; Liu et al., 2008; Stehman \& Milliken, 2007), or the evaluation of cropland ecosystem services via coupling with local net primary productivity data (Song, Deng, Yuan, Wang, \& Li, 2015, Song, Deng, Liu, Li \& Jin, 2015).

By virtue of its speed and growing ease for acquiring land cover information, remote sensing is now widely used for crop growth monitoring, yield prediction, and the extraction of crop type distributions. Remote sensing techniques led to several landmark programs concerning crop growth monitoring and yield prediction worldwide: the Large Area Crop Inventory Experiment (LACIE) in the USA since 1974 (Macdonald \& Hall, 1980; Pinter, Ritchie, Hatfield, \& Hart, 2003), the Agriculture and Resources Inventory Surveys Through Aerospace Remote Sensing (AGRISTARS) started in 1980 (Houston \& Hall, 1984), the Monitoring of Agriculture with Remote Sensing (MARS) by the European Union since 1988 (Perdigao, Vossen, \& Gallego, 1997), the Cropland Data Layer (CDL) program in the USA (Boryan, Yang, Mueller, \& Craig, 2011), and the Group on Earth Observations Global Agricultural Monitoring Initiative (GEOGLAM) that was launched by the Group of Twenty (G20) Agriculture Ministers in June 2011 (Whitcraft, Becker-Reshef, \& Justice, 2015). Separately, many scholars have since established crop growth models based on the remote sensing images to monitor crop growth from afar (Bouman, 1992; Clevers \& vanLeeuwen, 1996; Li \& Fox, 2012). For related purposes of yield prediction, remote sensing images have been used in a variety of ways to model and estimate crop yields (Becker-Reshef, Vermote, Lindeman, \& Justice, 2010; Lobell, 2013; Patel, Bhattacharjee, Mohammed, Tanupriya, \& Saha, 2006). Nevertheless, both crop growth monitoring and yield prediction are inherently based on crop type distribution data.

Along with technological advances, especially of improved sensors, the remote sensing images have also been significantly improved in their spatial, temporal, and spectral resolutions. This has empowered researchers to set out and extract more crop type distribution data based on remote sensing technology. Many scholars adopted the object-oriented method to identify crop distribution based on the abundant structure and texture information of remote sensing images at high spatial resolution (CastillejoGonzalez et al., 2009; Conrad, Fritsch, Zeidler, Rucker, \& Dech, 2010; Duro, Franklin, \& Dube, 2012; Torres-Sánchez, LópezGranados, \& Peña, 2015). The object-oriented classification method solved the problems of the 'salt-and-pepper' effects in crop classification that were generated by the traditional pixel-based method. Other scholars have classified crops based on their differing variation characteristics on the continuous spectrum of hyperspectral remote sensing images, by using a narrowed spectral range (Camps-Valls et al., 2003; Liu \& Bo, 2015; Mahesh, Jayas, Paliwal, \& White, 2015; Nidamanuri \& Zbell, 2011). However, both high spatial resolution and hyperspectral remote sensing images are generally applied to the single-phase extraction of crop type distribution in a small area of land, as their narrow scene size and non-free acquisition make it hard to obtain comparable mosaic images at larger spatial scales.

In the extraction of crop type distribution for a large spatial scale and a long time span, many scholars use remote sensing images with high temporal resolution at lower spatial resolution, which are easily acquired. In terms of methodology, the vegetation index time-series data of images from MODIS (Chen, Son, Chang, \& Chen, 2011; Lobell \& Asner, 2004; Zhang et al., 2015), NOAA/AVHRR (Atzberger \& Rembold, 2013; You, Meng, Zhang, \& Dong, 2013) or SPOT VEGETATION (Verbeiren, Eerens, Piccard, Bauwens, \& Van Orshoven, 2008), are normally adopted to identify the spatial distribution of different crops in combination with information about their phenology patterns. The wide coverage and frequent obtainment of such freely available images can indeed facilitate extracting crop type distribution over large regions. High temporal resolution remote sensing images are most suitable for the classification of simple crop sowing patterns in a region with a large field size (Sun, Xu, Lin, Zhang, \& Mei, 2012; Zhang, Lei, Wang, Li, \& Zhao, 2011). However, in those areas with fragmented cultivated land and rather complex crop planting patterns, the classification accuracy is usually unsatisfactory-because of the problem of mixed pixels - when MODIS or other high temporal resolution remote sensing images with low spatial resolution serve as the data source ( $\mathrm{Gu}$, Congalton, \& Pan, 2015; Jain, Mondal, DeFries, Small, \& Galford, 2013; Wu \& Li, 2012). Compared with these lower spatial resolution images, Thematic Mapper (TM) and Enhanced Thematic Mapper Plus (ETM+) images offer higher spatial resolution at a proper temporal resolution (30 $\mathrm{m}$ and 16 days, respectively). Hence, they are a more robust data source for the more precise extraction of crop type distribution in those study areas featuring fragmented cultivated land and complex crop sowing patterns. However, TM/ ETM+ images are seldom applied to the extraction of crop type distribution at large scales because of the great amount of preprocessing work required, and the lack of suitable extracting rules and methods.

Zhangye City is the most important irrigated agricultural area in the Heihe River Basin of arid northwest China. Although it is characterized by fragmented cultivated land and complex crop sowing patterns, surprisingly little attention has been paid to extracting crop type distribution for this crucial agricultural area. To this end, by using multi-temporal TM/ETM + images as the data source, we extracted crop type distribution for Zhangye City based on a decision tree classification method. The four objectives of this research were to (1) establish classification rules to extract the crop type distribution; (2) analyze and discern the spatial-temporal changes in crop type distribution; (3) discuss the landscape pattern changes of each crop in Zhangye City, in the period between 2007 and 2012; and (4) model the crop conversion potentials in 2017.

\section{Study area}

The Heihe River Basin, the second largest inland river basin in the arid region of northwest China, has a watershed area of $12.80 \times 10^{6}$ ha and a great deal of oases. With more than 2000 years of agricultural development, this river basin is one of the ten key commodity grain bases in northwest China. The study area, Zhangye City, which is situated at the middle reaches of the Heihe River Basin $\left(97^{\circ} 30^{\prime} \mathrm{E}-101^{\circ} 43^{\prime} \mathrm{E}, 37^{\circ} 55^{\prime} \mathrm{N}-40^{\circ} 00^{\prime} \mathrm{N}\right)$ in the central part of the Hexi Corridor, has abundant sunlight-heat resources, fertile soil, convenient irrigation, and plentiful water $\left(26.50 \times 10^{8} \mathrm{~m}^{3}\right)$ (Fig. 1). Zhangye City is the most developed agricultural area within the 


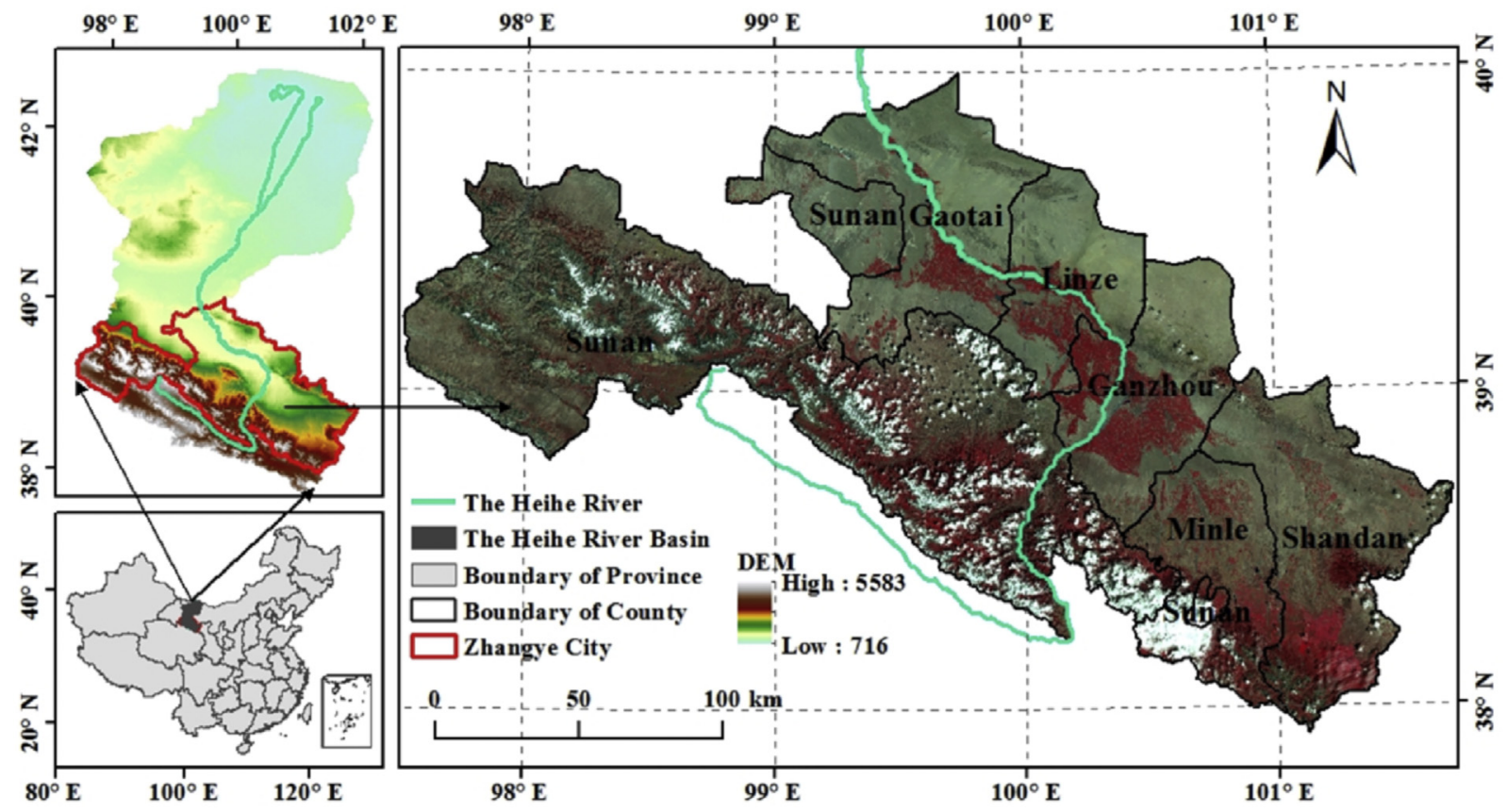

Fig. 1. The location of the study area.

Heihe River Basin, for which it accounts for $95 \%$ of the total cultivated land with an irrigation area of $0.24 \times 10^{6}$ ha. However, its cultivated land is fragmented with complex crop planting patterns. The sizes of its fields are mostly about $100 \mathrm{~m} \times 100 \mathrm{~m}$ (i.e., 1 ha) according to our field survey. The major crops of Zhangye City include corn, wheat, barley, oilseed rape, and vegetables, all of which are planted annually.

Zhangye City has a total land area of $3.55 \times 10^{6}$ ha, composed of five counties and one district under its jurisdiction: Shandan County, Minle County, Linze County, Gaotai County, Sunan Yugur Autonomous County (hereinafter abbreviated as "Sunan County") and the Ganzhou District (Fig. 1). The region has a typical temperate continental climate but with severe aridity. The annual precipitation in Zhangye City is only $140 \mathrm{~mm}$, while the annual potential evaporation is between $1600 \mathrm{~mm}$ and $2400 \mathrm{~mm}$, with a mean annual runoff of $24.75 \times 10^{8} \mathrm{~m}^{3}$, a mean annual temperature of $6-8{ }^{\circ} \mathrm{C}$, an annual sunshine duration of $3000-3600 \mathrm{~h}$, an average annual accumulated temperature of $2900{ }^{\circ} \mathrm{C}$, and a frost-free season lasting 112-145 days. Agricultural irrigation water of Zhangye City comes mainly from the melted ice and snow of the Qilian Mountains and from local rainfall, but these two inputs feature spatial-temporal unevenness. The water supply is distributed unevenly during the year, being concentrated in July and August. Spatially, more agricultural irrigation water is available to Ganzhou, Linze, and Gaotai counties than Shandan, Minle, and Sunan counties because the former group has a larger irrigation water quota (Zhou, Wu, \& Zhang, 2015), a more convenient groundwater irrigation system, and is located at a lower altitude that provides higher groundwater levels.

\section{Data and methods}

\subsection{Data sources}

\subsubsection{Satellite data and preprocessing}

The remote sensing images used in this research were TM/ ETM+ images from satellites Landsat 5 and Landsat 7, with a swath width of $185 \mathrm{~km}$, a spatial resolution of $30 \mathrm{~m}$, and a temporal resolution of 16 days. All images were Level 1T products after systematic radiometric and geometric corrections (USGS, 2007; USGS, 2012). Six images comprised the entire image of Zhangye City, and their corresponding path/row numbers were 133/33, 133/34, 134/ $32,134 / 33,135 / 32$, and $135 / 33$. We selected 42 high-definition TM/ ETM+ images from 2007, to 60 ETM+ images from 2012: both image sets had $<10 \%$ cloud coverage.

After radiometric calibration these images were converted to surface reflectance using the atmospheric correction module, the Fast Line-of-sight Atmospheric Analysis of Spectral Hypercubes (FLAASH). De-striping was applied for ETM+ images using the Landsat-Gapfill tool, which is a multi-scale segment model that guides interpolation of spectral data across gaps in Landsat 7 SLCoff images. After projection transformation and image mosaicking, seven and ten mosaic images were generated for 2007 and 2012, respectively (Table 1 ).

The cultivated land boundaries of Zhangye in 2007 and 2012 served as a mask to avoid the misclassification of crops from other vegetation. These boundaries were demarcated through a visual interpretation of the TM/ETM+ images.

\subsubsection{Other data and processing}

Other auxiliary data in this research include crop phenophase, crop samples, and driver variables. The data on crop phenophase in Zhangye City came from two sources: the website of the Department of Crop Production in the Ministry of Agriculture of China (DCPMOAC, 2012), and our own field questionnaire survey.

Table 1

TM/ETM+ mosaic images of Zhangye in 2007 and 2012.

\begin{tabular}{ll}
\hline Year & Image time distribution \\
\hline 2007 & $(4,2),(6,2),(7,2),(8,2),(9,2),(10,1),(10,2)$ \\
2012 & $(4,2),(6,1),(6,2),(7,2),(8,1),(8,2),(9,1),(9,2),(10,1),(10,2)$ \\
\hline
\end{tabular}

Notes: $(\mathrm{x}, \mathrm{y})$ represents the time phase of images, wherein $\mathrm{x}$ represents the month, and $y \in\{1,2\}$ represents the first and second half of a month respectively. 
Crop samples in 2012 were sourced from the "Heihe Watershed Allied Telemetry Experimental Research (HiWATER): Land Cover Map of Heihe River Basin" dataset in the Data Management Center of the Heihe River Project of China (DMCHRPC, 2012; Zhong et al., 2014). The dataset was obtained from HJ-1/CCD images, which were collected by the environment and disaster monitoring small satellite of China launched in 2008, at both high spatial resolution (30 $\mathrm{m}$ ) and high temporal resolution (2 days). The classified crops in this dataset included corn, wheat, barley, oilseed rape, and 'others'. A stratified pure pixel sampling approach generated 40 classification samples and 50 other verification samples of corn, wheat, barley, and oilseed rape covering the whole study area, each with a sample size of $3 \times 3$ pixels $\left(=90 \times 90 \mathrm{~m}^{2}\right)$.

Variables used to model the crop conversion potentials included elevation, slope, precipitation, temperature, distance to roads, distance to rivers, and distance to settlement places. Data on elevation and slope were obtained from the Digital Elevation Model (DEM) dataset (GDCC, 2012); the data on annual average precipitation and temperature came from the spline interpolation of the meteorological data (MDSSSC, 2012); the data on distance to roads, distance to rivers, and distance to settlement places were obtained from the " HiWATER: Land Cover Map of Heihe River Basin" dataset (DMCHRPC, 2012; Zhong et al., 2014).

\subsection{Research method}

\subsubsection{Multi-temporal NDVWI}

The Normalized Difference Vegetation Index (NDVI) (Huete et al., 2002) characterizes vegetation growth conditions in a simple and effective manner; hence, it has been widely used in monitoring seasonal and inter-annual changes of vegetation growth. NDVI is a vital index for vegetation-related classification in that it strongly correlates with leaf area index, vegetation coverage, and vegetation conditions. Similarly, the Normalized Difference Water Index (NDWI) (Gao, 1997) - which is more sensitive to the changes in liquid water content of vegetation canopies but less sensitive to atmospheric effects when compared with NDVI-has been widely used in vegetation classification, especially for arid land regions. Both NDVI and NDWI are dimensionless, ranging from -1 to 1 . In addition, the Normalized Difference VegetationWater Index (NDVWI), a new index integrates both NDVI and NDWI, was developed by us. The formulas for NDVI NDWI, and NDVWI are as follows:

$$
\begin{aligned}
& N D V I=[\rho(\text { nir })-\rho(\text { red })] /[\rho(\text { nir })+\rho(\text { red })] \\
& N D W I=[\rho(\text { nir })-\rho(\text { swir })] /[\rho(\text { nir })+\rho(\text { swir })] \\
& N D W W I=N D V I+N D W I=\frac{\rho(\text { nir })-\rho(\text { red })}{\rho(\text { nir })+\rho(\text { red })}+\frac{\rho(\text { nir })-\rho(\text { swir })}{\rho(\text { nir })+\rho(\text { swir })}
\end{aligned}
$$

where $\rho$ (red), $\rho$ (nir), and $\rho$ (swir) represent the surface reflectance at the red, near-infrared, and short wave infrared bands, respectively. These bands of TM/ETM + images are the third, fourth, and fifth bands, respectively.

The Optimum Index Factor (OIF), which is based on the variance and the correlation among the different bands of multi-spectral remote sensing images, is widely used for the optimal selection of band combinations (Chavez, Berlin, \& Sowers, 1984). The larger the OIF value, the more information and smaller correlation the multi-spectral bands have.

However, the OIF evaluates the separability of color composite images containing only three bands. Therefore a new index, the
Optimum Index Factor of Multi-temporal images (OIFM), was generated to evaluate the separability of multi-temporal images. The formulas for OIF and OIFM are as follows:

$$
\begin{aligned}
& \text { OIF }=\sum_{i=1}^{3} S D_{i} / \sum_{j=1}^{3}\left|C C_{i j}\right| \\
& \text { OIFM }=\sum_{i=1}^{m} S D_{i} / \sum_{j=1}^{m}\left|C C_{i j}\right|
\end{aligned}
$$

where $S D_{i}$ represents standard deviation for band $I ;\left|C C_{i j}\right|$ represents the absolute value of the correlation coefficient between bands $i$ and $j$; and $m$ represents the number of time-windows of the multitemporal images.

We evaluated the OIFM of different multi-temporal spectral index images; e.g. NDVI, NDWI, and NDVWI. The largest OIFM value was obtained from the multi-temporal NDVWI images (0.150): this indicated that it was more useful for crop classification than NDVI (0.094) and NDWI (0.070), and so it was selected to carry our analyses further.

\subsubsection{Time-window selection}

Based on the Multi-temporal TM/ETM+ mosaic images and the surveyed crop samples, the NDVI and NDWI time-series curves of corn, wheat, barley, and oilseed rape were constructed. The standard time-series curve, i.e. an average curve of the same crop samples, was also generated to depict the seasonal changes of a crop type throughout its phenophase (Fig. 2). Based on the NDVI and NDWI standard time-series curves and the phenophase information of different crops, the key time-windows for identifying crop type were selected. However, as crop samples in 2007 could not be surveyed, the key time-windows in 2007 were estimated with the NDVI and NDWI standard time-series curves in 2012.

In Zhangye, corn and oilseed rape are autumn crops while wheat and barley are summer crops. The sowing and harvest stages of summer crops are in May and August, respectively, much earlier than that of autumn crops (i.e., April and September, respectively). Hence, this difference in timing could be used to reliably separate autumn crops from summer crops. However, because the cloudfree TM/ETM+ images in May of 2007 and 2012 failed to entirely cover Zhangye City, this time phase could not be used for interpretation. Thus, the time phases of " $(8,2)$ " in 2007 and of " $(8,1)$ " in 2012 were selected as the key time-windows to separate corn and oilseed rape from wheat and barley. In this step, both the identified autumn crops (corn and oilseed rape) and summer crops (wheat and barley) contained the category of 'other crops' (i.e., those crops sowed in Zhangye that were not varieties of corn, wheat, barley, and oilseed rape).

The significant difference of the NDVI and NDWI standard timeseries curves between corn and oilseed rape distinguished the two crop types. Corn was sowed in late April, half a month earlier than oilseed rape. The NDVI and NDWI of oilseed rape are thus slightly larger than those of corn at each of the corresponding time phases of "(6,1)", "(6,2)", and "(7,2)" (Fig. 2). After the milk stage, the oilseed rape NDVI and NDWI were obviously smaller than that of corn, especially in September. For this reason, the time phases of " $(9,2)$ " in 2007 and " $(9,1)$ " in 2012 were selected as the key timewindows to separate corn from oilseed rape. The key timewindows of " $(7,2)$ " and " $(8,2)$ " in 2007 , and " $(6,2)$ ", " $(7,2)$ ", " $(8,1)$ ", and " $(8,2)$ " in 2012 , were selected to separate corn and oilseed rape from the group of other crops.

The NDVI and NDWI standard time-series curves of wheat and barley were so similar that it was difficult to use a single time- 


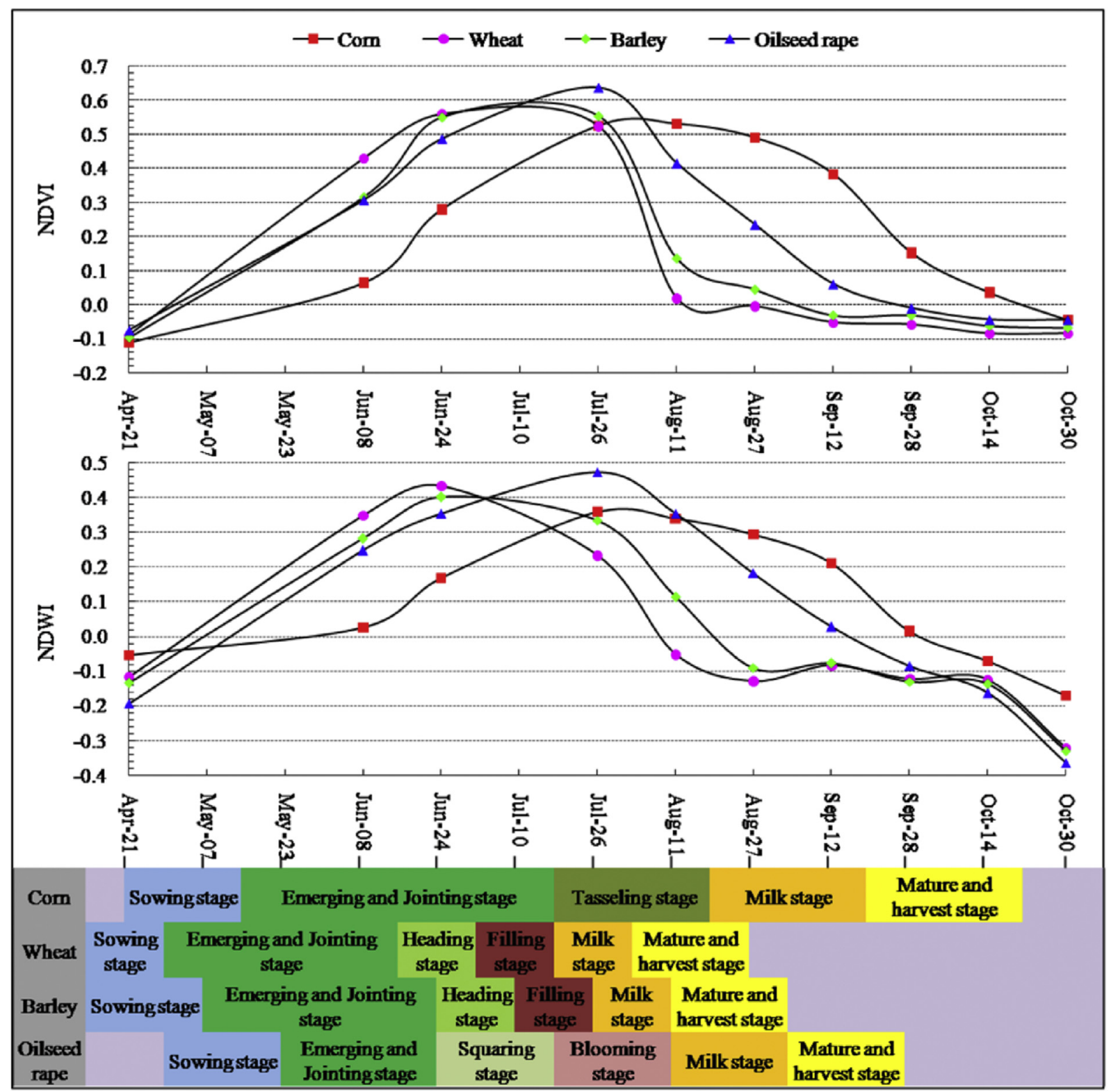

Fig. 2. NDVI and NDWI standard time-series curve and phenophase of crops in Zhangye in 2012.

window to separate these two crops. At the time phase " $(6,1)$ ", the NDVI and NDWI of wheat were larger than that of barley, but this was reversed at the time phase " $(8,1)$ ". In addition, the NDVI and NDWI of the two crops were approximate at phases " $(6,2)$ " and " $(7,2)$ ". Therefore, the time phases " $(6,2)$ " and " $(8,2)$ " in 2007 , and "(6,1)" and "(6,2)" in 2012, were selected as the key time-windows to separate wheat from barley. Subsequently, the key timewindows of " $(6,2)$ ", “( 7,2$)$ ", " $(8,2)$ ", and " $(9,2)$ " in 2007 , and "( 6,2$)$ " and " $(7,2)$ " in 2012 , were selected to separate wheat and barley from the group of other crops.

So, altogether, the time phases of " $(6,2)$ ", “( 7,2$)$ ", " $(8,2)$ ”, and

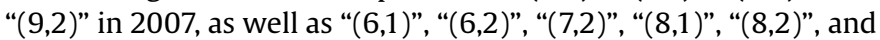
" $(9,1)$ " in 2012 , were selected as the key time-windows for identifying crop type distribution in 2007 and 2012.

\subsubsection{Decision tree classification}

Decision tree classification is a recursive method to sequentially classify remote sensing images at nodes using a series of 'if-thenelse' rules. These classification rules can be obtained through either the supervised learning of training samples or empirical knowledge (Friedl \& Brodley, 1997; Pal \& Mather, 2003; Tayyebi \& Pijanowski, 2014; Tayyebi, Pijanowski, Linderman, \& Gratton, 2014). The topdown classification process of a decision tree is capable of breaking down a complex classification into a set of simpler multistage decisions. The classification process is thus easy to understand and well matched to human cognition.

Due to the diverse sowing locations and timing of a crop type, individual crop growth conditions are inevitably different. Accordingly, each key time-window's threshold value should be set according to the NDVI time-series curves of all representative crop classification samples spread over Zhangye City. These representative crop classification samples were collected via stratified sampling. By using all the key time-windows and their threshold values, the classification rules for the spatial distribution extraction of corn, wheat, barley, and oilseed rape in Zhangye City in 2007 and 2012 were determined. Since only four key time-windows in 2007 were selected while six were selected in 2012, the classification rules of these crops for 2007 and 2012 were not exactly the same. 
To classify crops classification, a decision tree was established based on the determined classification rules (Fig. 3). When identifying crop types, corn and oilseed rape were first separated from wheat and barley. Then a further separation was made between corn and oilseed rape, or between wheat and barley.

\subsubsection{Processing after classification}

After completing crop classification, the removal of small patches and an accuracy assessment were carried out. From the perspective of either thematic mapping or practical application, it is necessary to remove these unavoidable small patches in classification results. In this study a majority analysis method-similar to convolution filtering, which classifies spurious pixels of a small patch into the class of a large ambient patch-was used for removing small patches. After setting the kernel size and center pixel weight, the class of the center pixel in the kernel can be replaced with the class of the majority pixels in the kernel. The center pixel weight represents the calculation times of the center pixel. The larger the kernel is, the smoother the processing effect will be; the larger the center pixel weight is, the less likely it is to classify the center pixel into other classes. The kernel size of our research was set at $3 \times 3$ pixels, according to the field size of
Zhangye City, with a center pixel weight set at five.

An accuracy assessment is a test of the dependability of the classification results via contrasts with a real or empirical reference source, one which can be obtained from field surveys, high-spatialresolution remote sensing images, or other high-accuracy classification results. In this study, based on the land cover data in June of 2012 (DMCHRPC, 2012; Zhong et al., 2014), 50 verification samples each for corn, wheat, barley, and oilseed rape were selected as the real reference source using a stratified pure pixel sampling method. An accuracy assessment was performed based on the error matrix method (Congalton, 1991; Gu et al., 2015); and the mapping accuracy, user accuracy, overall accuracy, and Kappa coefficient of the crop classification results in Zhangye City of 2012 were also all calculated.

\subsubsection{Landscape indices}

Cultivated land is a kind of typical artificial landscape, which variously combines the influences of human society and the natural environment. Cultivated land is directly affected by human activities of agricultural production. Landscape indices efficiently reflect landscape composition and configuration, which is known to affect ecological processes both independently and interactively

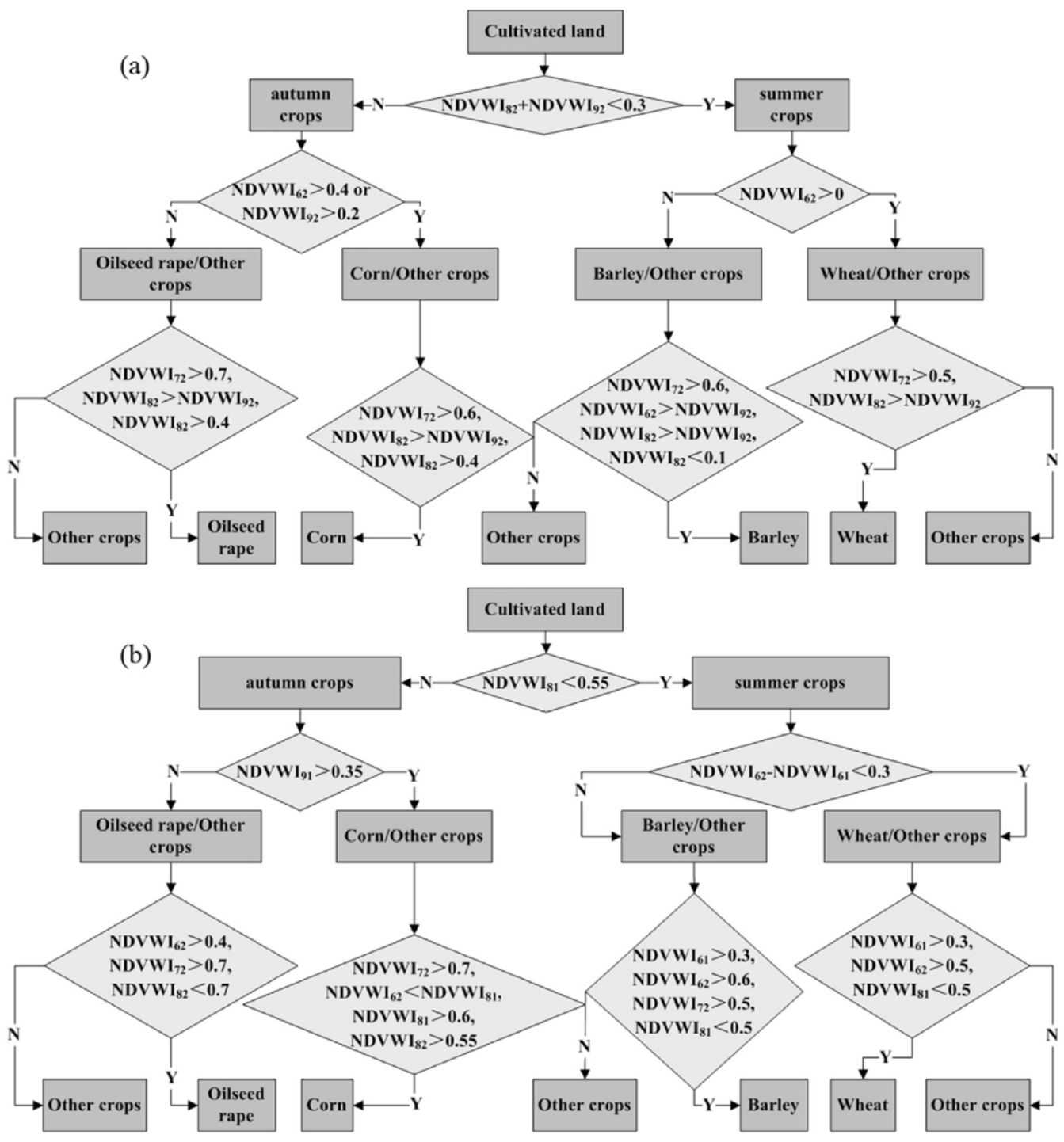

Fig. 3. Decision tree of crop classification in Zhangye in 2007 (a) and 2012 (b). 
(Mcgarigal \& Marks, 1995). In this study, some well known landscape indices were quantified to analyze the landscape pattern of staple crops, namely mean patch size (MPS), largest patch index (LPI) and edge density (ED) of the class level, and contagion index (CONTAG) and Shannon's diversity index (SHDI) of the landscape level (Mcgarigal \& Marks, 1995; Su, Yang, Hu, Luo, \& Wang, 2014; Wan, Zhang, Zhang, Qi, \& Na, 2015). Their formulas are as follows:

MPS represents the average area considering all patches of a particular type. It is an effective landscape index to estimate the degree of fragmentation for a particular landscape type, with a lower MPS showing a higher level of fragmentation. It is expressed in hectare units, with a range of $(0, \infty)$.

$M P S_{i}=\frac{C A_{i}}{N P_{i}}$

LPI quantifies the percentage of total landscape area contributed by the largest patch of the corresponding patch type; it is a simple measure of dominance. It is expressed in percent units, with a range of $(0,100)$.

$L P I_{i}=\frac{L P A_{i}}{T A} * 100$

ED shows the edge length of a crop type on a per unit area basis, which facilitates comparison among landscapes of varying sizes. It is expressed in units of meters per hectare, with a range of $(0, \infty)$.

$E D_{i}=\frac{C E_{i}}{T A}$

CONTAG describes the reunion degree or extending trend of a landscape. It is expressed in percent units, with a range of $(0,100)$.

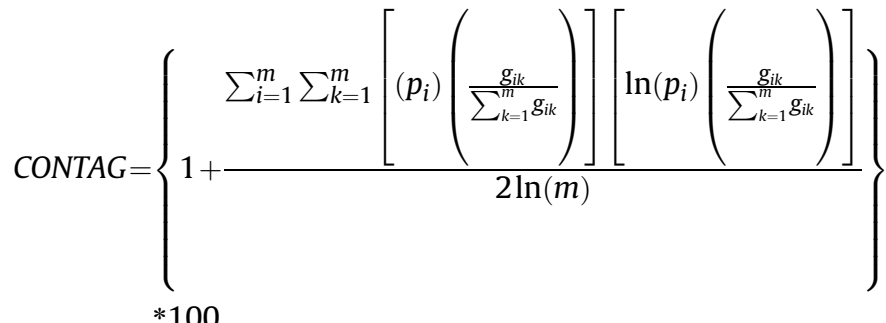

SHDI is a popular measure of diversity in community ecology, and its value is dimensionless, with a range of $(0, \infty)$.

$S H D I=-\sum_{i=1}^{m}\left(p_{i} \ln p_{i}\right)$

where $M P S_{i}, L P I_{i}$, and $E D_{i}$ represent mean patch size, largest patch index, and edge density of the particular crop $i$, respectively. CONTAG and SHDI represent contagion index and Shannon's diversity index of cultivated land landscape, respectively. $C A_{i}, N P_{i}, C E_{i}$, and $L P A_{i}$ represent crop area, total number of patches, total edge length, and largest patch area of the crop $i$, respectively. $T A$ represents the total area of the cultivated landscape; $p_{i}$ represents the proportion of the cultivated landscape occupied by crop $i ; m$ represents number of crop types present in the cultivated landscape; $g_{i k}$ represents number of adjacencies between pixels of crop types $i$ and $k$ based on the double-count method.

\subsubsection{Land Change Modeler for conversion potentials}

Accurately modeling crop conversion potentials is an essential step in the process of predicting changes in crop type distribution. In this study, we used the Land Change Modeler (LCM) within
TerrSet, which provides a series of empirically evaluated conversion sub-models, to model the potentials for crop conversions (Sangermano, Eastman, \& Zhu, 2010).

First, the driver variables of elevation, slope, precipitation, temperature, distance to roads, distance to rivers, and distance to settlement places were selected to establish the conversion submodels. The meteorological variables of precipitation and temperature directly provide indispensable natural resources for crop growth (e.g., water, light, and heat). The socio-economic variables of distance to rivers, distance to roads, and distance to settlement places, reflect the irrigation, trade, and consumption conditions of crops that indirectly affected crop type distribution. A sub-model includes several types of crop conversions sharing the same drivers. These drivers ought to be eligible in an availability test before being added to the model. This quick test provides a strong evaluation for the potential explanatory power of the variables using a measure of Cramer's V Coefficient.

Subsequently, a feed-forward non-parametric method, i.e. the Multi-Layer Perceptron (MLP) neural network, which consists of an input layer, a hidden layer, and an output layer, was performed to run conversion sub-models and to create crop conversion potentials. The MLP has a demonstrated advantage over many other methods, e.g. the Weights of Evidence in DINAMICA, empirical probabilities in GEOMOD, and logistic regression in CLUE-S, especially for solving nonlinear simulations and classifications (Sangermano et al., 2010).

\section{Results}

\subsection{Accuracy assessment of crop classification}

By comparing the selected verification samples with the classification result of crop type distribution in 2012, an error matrix was established to assess the classification accuracy (Table 2). (It should be noted that the accuracy assessment was not performed in 2007 for a lack of verification samples.) The overall accuracy and the Kappa coefficient of classification in 2012 were as high as $89.38 \%$ and 0.8672 , respectively. In particular, the classification accuracy of corn reached a remarkable $96.00 \%$. Only a few corns were misclassified as 'other crop'. The classification accuracy of wheat, barley, oilseed rape, and the group of other crops were $88.67 \%, 88.00 \%, 91.11 \%$, and $83.11 \%$, respectively. Only a few misclassifications occurred between wheat and barley due to their similar phenophases.

\subsection{Changes in the sowing area and proportion of crops}

The cultivated land area in Zhangye City increased from $463.81 \times 10^{3}$ ha in 2007 to $493.89 \times 10^{3}$ ha in 2012 , despite the implemented 'grain-for-green' policy (Table 3). The most significant changes in crop areas from 2007 to 2012 in Zhangye were the expansion of corn (51.47\%) and oilseed rape (47.28\%), and the shrinkage of wheat (10.50\%) and barley (36.44\%). The sowing area of corn and oilseed rape increased by $39.21 \times 10^{3}$ ha and $5.99 \times 10^{3}$ ha, while that of wheat and barley decreased by $3.61 \times 10^{3}$ ha and $9.14 \times 10^{3}$ ha from 2007 to 2012 , respectively. These changes in crop sowing areas were driven by the comparative economic benefits of various crops and the spatial-temporal distribution characteristics of agricultural irrigation water. The sown proportion of corn and oilseed rape increased from $16.24 \%$ to $2.73 \%$ in 2007 to $23.36 \%$ and $3.78 \%$ in 2012 , respectively. However, the proportion of wheat and barley decreased from $7.42 \%$ to $5.41 \%$ in 2007 to $6.23 \%$ and $3.23 \%$ in 2012 , respectively. In addition, the planting area of other crops in Zhangye City decreased, albeit by only $2.37 \times 10^{3}$ ha $(0.75 \%)$. 
Table 2

Error matrix between verification samples and classification result in 2012 .

\begin{tabular}{|c|c|c|c|c|c|c|c|c|}
\hline & & \multicolumn{5}{|c|}{ Reference data for verification } & \multirow[t]{2}{*}{ Total } & \multirow[t]{2}{*}{ User accuracy (\%) } \\
\hline & & Corn & Wheat & Barley & Oilseed rape & Other crops & & \\
\hline \multirow[t]{5}{*}{ Classification result } & Corn & 432 & 0 & 0 & 13 & 42 & 487 & 88.71 \\
\hline & Wheat & 0 & 399 & 36 & 0 & 19 & 454 & 87.89 \\
\hline & Barley & 0 & 51 & 396 & 2 & 1 & 450 & 88.00 \\
\hline & Oilseed rape & 0 & 0 & 0 & 410 & 14 & 424 & 96.70 \\
\hline & Other crops & 18 & 0 & 18 & 25 & 374 & 435 & 85.98 \\
\hline Total & & 450 & 450 & 450 & 450 & 450 & 2250 & \\
\hline Mapping accuracy (\%) & & 96.00 & 88.67 & 88.00 & 91.11 & 83.11 & & \\
\hline
\end{tabular}

Notes: The overall accuracy is $89.38 \%$; the Kappa coefficient is 0.8672 .

Table 3

Changes in sowing area $\left(10^{3}\right.$ ha) and proportion (\%) of crops in Zhangye from 2007 to 2012.

\begin{tabular}{|c|c|c|c|c|c|c|}
\hline \multirow[t]{2}{*}{ Types } & \multicolumn{2}{|l|}{2007} & \multicolumn{2}{|l|}{2012} & \multicolumn{2}{|c|}{ Changes from 2007 to 2012} \\
\hline & Sowing area & Sowing proportion & Sowing area & Sowing proportion & Sowing area & Sowing proportion \\
\hline Corn & 76.18 & 16.24 & 115.39 & 23.36 & 39.21 & 6.94 \\
\hline Wheat & 34.40 & 7.42 & 30.79 & 6.23 & -3.61 & -1.18 \\
\hline Barley & 25.08 & 5.41 & 15.94 & 3.23 & -9.14 & -2.18 \\
\hline Oilseed rape & 12.67 & 2.73 & 18.67 & 3.78 & 5.99 & 1.05 \\
\hline Other crops & 315.47 & 68.02 & 313.10 & 63.39 & -2.37 & -4.62 \\
\hline Cultivated land & 463.81 & 100.00 & 493.89 & 100.00 & 30.08 & 0.00 \\
\hline
\end{tabular}

The main stream of the Heihe River flows through Ganzhou, Linze, and Gaotai. The elevation of these three counties is also low, strongly suggesting that their agricultural irrigation water was more abundant than that available to other counties in Zhangye City. The irrigation water demand of corn exceeds that of wheat, barley, or oilseed rape. Therefore, corn was mainly sowed in Ganzhou, Linze, and Gaotai for which the sown area of corn continuously increased by $12.86 \times 10^{3}$ ha, $4.03 \times 10^{3}$ ha and $5.77 \times 10^{3}$ ha from 2007 to 2012 , respectively (Table 4). Among these three counties, the sown area of corn in Ganzhou was the largest. However, the increases of corn in Minle (728.88\%) and Shandan (5479.80\%) were faster than those in Ganzhou (29.12\%). Wheat was mainly sowed in Minle and Ganzhou in 2007, but this sowing shifted to Minle and Shandan in 2012. The sown area of wheat increased by $5.26 \times 10^{3}$ ha in Shandan while it decreased by $4.93 \times 10^{3}$ ha and $3.25 \times 10^{3}$ ha in Minle and Ganzhou from 2007 to 2012, respectively. Although barley and oilseed rape were both mainly distributed in Minle and Shandan, the sown areas of the two crops changed in an opposite trend from 2007 to 2012. The sown area of barley in Minle and Shandan decreased by $5.06 \times 10^{3}$ ha and $5.06 \times 10^{3}$ ha, whereas that of oilseed rape in the two counties increased by $7.37 \times 10^{3}$ ha and $2.86 \times 10^{3}$ ha, respectively. In Sunan, where livestock farming is the dominant form of agricultural production, the crop-sown area there is relatively small.

From 2007 to 2012, the sown proportions and their respective changes of the four main crop types in the six counties (districts) displayed distinctive features (Table 4). In Minle, wheat was the most widely distributed crop. However, the sown proportion of wheat and barley there decreased by $5.23 \%$ and $4.87 \%$ while that of corn and oilseed rape increased by $7.96 \%$ and $5.91 \%$, respectively. The sown proportion of corn, wheat, and oilseed rape in Shandan increased by $6.59 \%, 4.90 \%$, and $2.65 \%$, respectively, while that of barley decreased from $10.15 \%$ in 2007 to $5.28 \%$ in 2012. The sown proportion of corn in Ganzhou increased by $7.55 \%$, while that of wheat decreased by $2.88 \%$. The sown proportion of corn in Linze and Gaotai increased from $34.25 \%$ to $20.68 \%$ in 2007 to $39.96 \%$ and $30.31 \%$ in 2012 , while the sown proportion of corn and wheat in Sunan decreased by $3.82 \%$ and $0.52 \%$, respectively.

On the whole, apart from livestock-based Sunan, the sown proportions of corn in the other five counties all increased from 2007 to 2012. Since the economic benefits of corn are greatest among crop types, farmers in Zhangye City prefer to sow corn if natural conditions permit it. Furthermore, in the period of 2007-2012, the sown areas of corn in Ganzhou, Linze, and Gaotai were much larger than those of Minle and Shandan, likely due to their spatial differences in irrigation water distributions.

\subsection{Changes in the spatial distribution of crops}

Corn was the predominant crop in Zhangye in both 2007 and 2012, followed by wheat (Fig. 4). In a spatial context, corn gradually expanded to Linze and Gaotai in 2012 from Ganzhou in 2007. In addition, a small number of corn cultivations were detected in the border area between Minle and Shandan. Global warming has driven the expansion of corn cultivation from flat areas to mountain areas, and from low latitude areas to high latitude areas. Wheat was

Table 4

Changes in sowing area $\left(10^{3} \mathrm{ha}\right)$ and proportion (\%) of crops in various counties (districts) of Zhangye from 2007 to 2012.

\begin{tabular}{|c|c|c|c|c|c|}
\hline \multirow[t]{2}{*}{ Counties } & \multicolumn{5}{|c|}{ Changes in crop sowing area (and proportion) } \\
\hline & Corn & Wheat & Barley & Oilseed rape & Other crops \\
\hline Minle & $9.83(7.96)$ & $-4.93(-5.23)$ & $-5.06(-4.87)$ & $7.37(5.91)$ & $0.01(-3.78)$ \\
\hline Shandan & $7.03(6.59)$ & $5.26(4.90)$ & $-5.06(-4.86)$ & $2.86(2.65)$ & $-8.76(-9.27)$ \\
\hline Ganzhou & $12.86(7.55)$ & $-3.25(-2.88)$ & $0.97(0.74)$ & $-3.65(-3.14)$ & $1.44(-2.28)$ \\
\hline Linze & $4.03(5.72)$ & $0.13(0.21)$ & $0.01(0.01)$ & $-0.78(-1.44)$ & $-1.10(-4.50)$ \\
\hline Gaotai & $5.77(9.63)$ & $-0.82(-1.55)$ & $0.00(0.00)$ & $0.13(0.22)$ & $-3.06(-8.31)$ \\
\hline Sunan & $-0.32(-3.82)$ & $-0.01(-0.52)$ & $0.01(0.03)$ & $0.06(-0.27)$ & $9.10(4.58)$ \\
\hline
\end{tabular}


mainly planted in the south of Ganzhou and the west of Minle in 2007. From 2007 to 2012, however, wheat showed a significant southward expansion, i.e. concentrating in the middle of Minle and the north of Shandan. The distribution of barley is quite fragmented due to the intervention of human productive activities. Barley was mainly distributed in the middle of Minle and the north of Shandan in 2007. In 2012, the barleys showed a fragmented trend, as their distribution scattered into the middle of these two counties. In addition, the oilseed rape had a scattered distribution in the middle of Minle and Shandan in 2007, whereas it became concentrated in the southeast of Minle and the southwest of Shandan in 2012. In sum, spatial changes of crop types in Zhangye were driven by the spatial-temporal unevenness of agricultural irrigation water, the comparative economic benefits of individual crop types, and the background effects of ongoing global warming.

\subsection{Conversion of crop sowing type}

From 2007 to 2012, the conversions of crop type mainly occurred among the four major crops (corn, wheat, barley, and oilseed rape) and the group of other crops (Table 5). The areas of other crops since converted to corn, wheat, barley, and oilseed rape were $49.72 \times 10^{3}$ ha, $10.91 \times 10^{3}$ ha, $6.05 \times 10^{3}$ ha, and $13.29 \times 10^{3}$ ha, respectively, which correspondingly accounted for

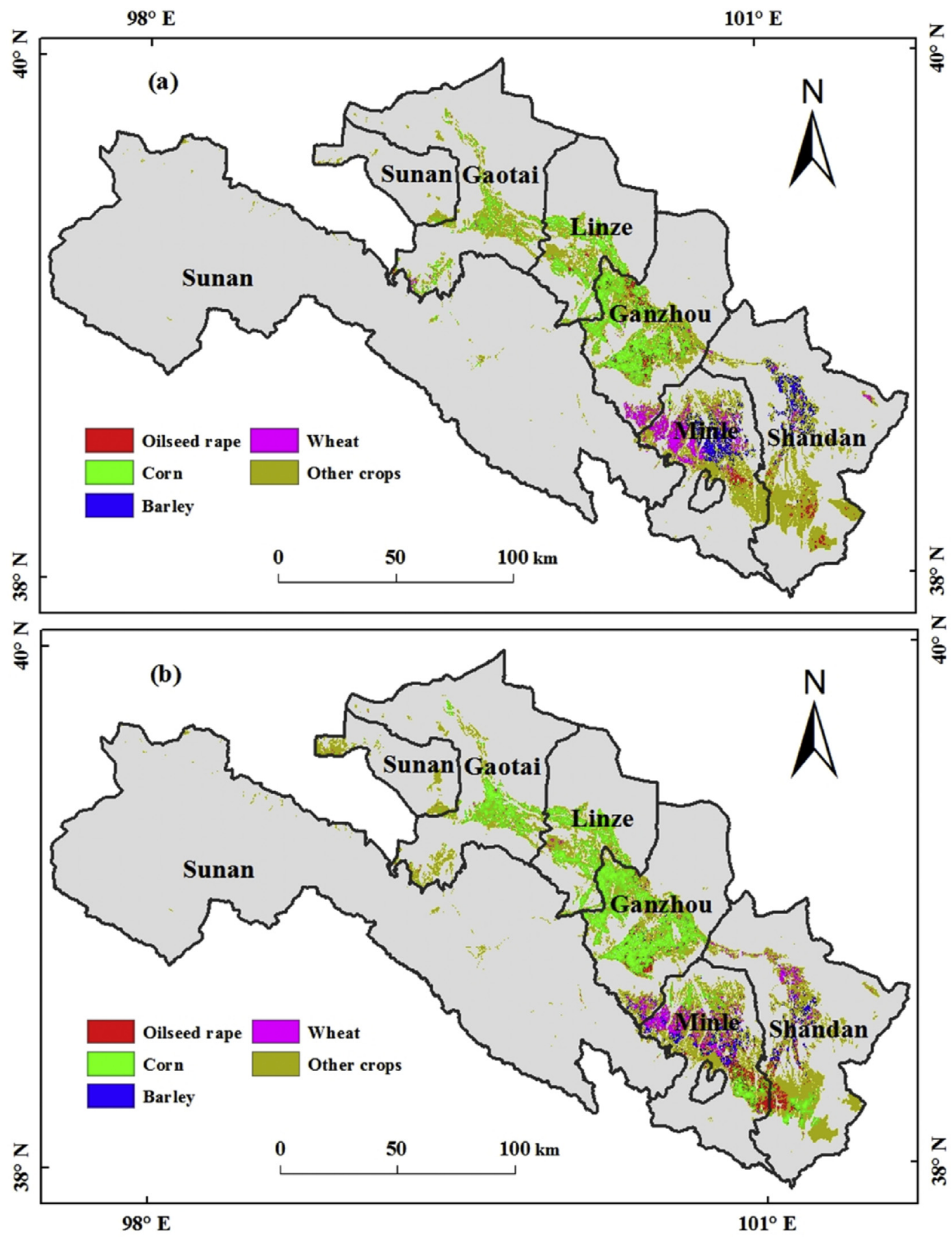

Fig. 4. Spatial distribution of the crops in Zhangye in 2007 (a) and 2012 (b). 
Table 5

Conversion matrix of crop type in Zhangye City from 2007 to 2012 ( $10^{3}$ ha).

\begin{tabular}{|c|c|c|c|c|c|c|c|c|}
\hline & & \multicolumn{6}{|c|}{ Gains in 2012} & \multirow[t]{2}{*}{ Total } \\
\hline & & Corn & Wheat & Barley & Oilseed rape & Other crops & Other land types & \\
\hline \multirow[t]{6}{*}{ Losses in 2007} & Corn & & 0.29 & 0.16 & 1.76 & 18.95 & 0.06 & 21.22 \\
\hline & Wheat & 2.48 & & 4.78 & 1.29 & 13.82 & 0.11 & 22.48 \\
\hline & Barley & 0.77 & 7.24 & & 0.77 & 11.56 & 0.06 & 2.40 \\
\hline & Oilseed rape & 6.77 & 0.10 & 0.21 & & 4.03 & 0.05 & 11.16 \\
\hline & Other crops & 49.72 & 10.91 & 6.05 & 13.29 & & 4.90 & 84.25 \\
\hline & Other land types & 0.70 & 0.31 & 0.06 & 0.05 & 34.13 & & 35.25 \\
\hline Total & & 60.44 & 18.85 & 11.26 & 17.16 & 82.49 & 5.18 & \\
\hline
\end{tabular}

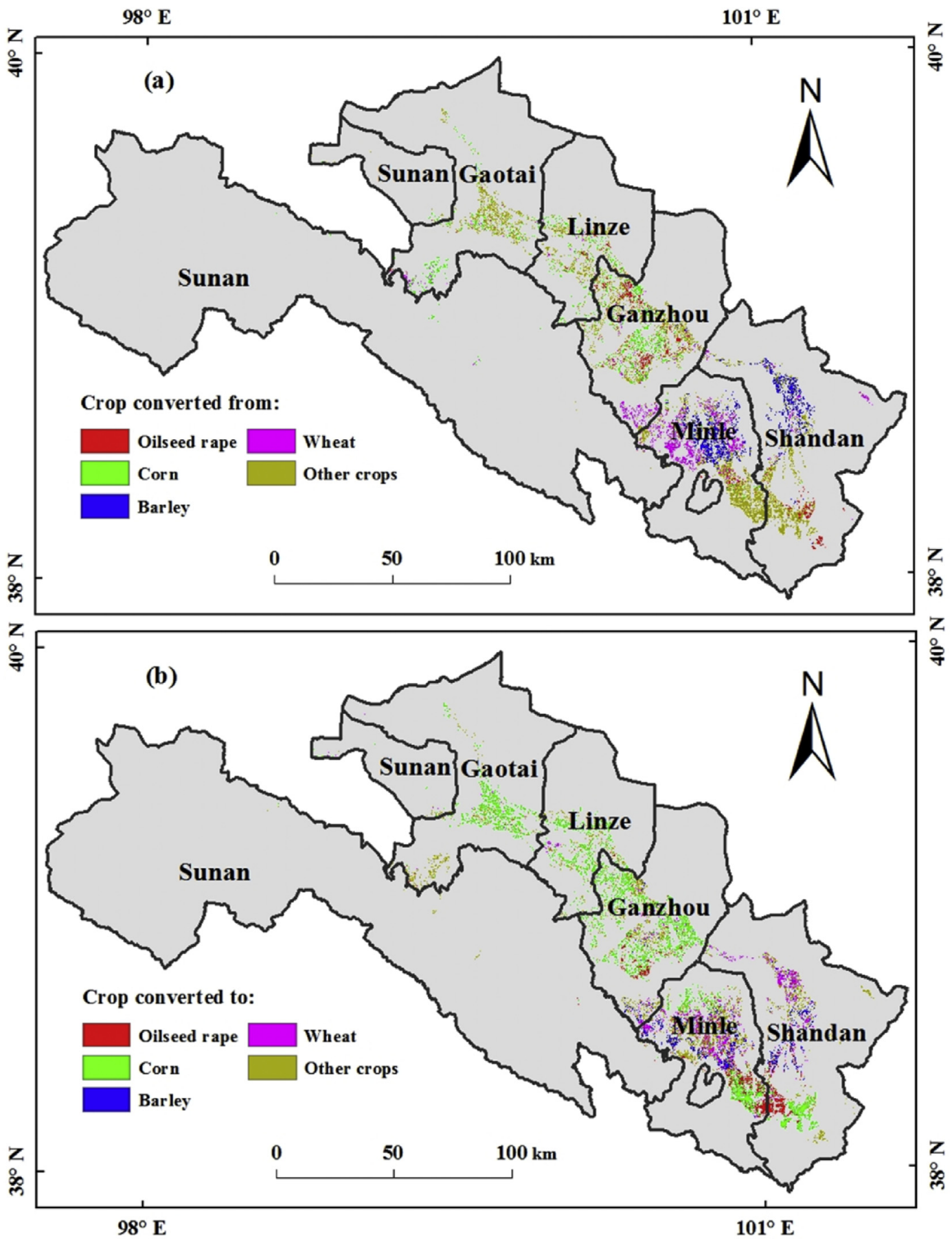

Fig. 5. Crop conversions from 2007 to 2012 in Zhangye. 
$43.09 \%, 35.43 \%, 37.93 \%$, and $71.21 \%$ of their total sown areas in 2012 . In addition, the area of other crops converted from corn, wheat, barley, and oilseed rape reached $18.95 \times 10^{3}$ ha, $13.82 \times 10^{3}$ ha, $11.56 \times 10^{3}$ ha, and $4.03 \times 10^{3}$ ha, respectively.

However, inter conversions among the four main crops were few (Table 5). The area of corn converted to wheat, barley, and oilseed rape were relatively low, at $0.29 \times 10^{3}$ ha, $0.16 \times 10^{3}$ ha, and $1.76 \times 10^{3}$ ha, respectively, which correspondingly accounted for $1.38 \%, 0.76 \%$, and $8.13 \%$ of the total converted area of corn. The area of wheat converted to corn, barley, and oilseed rape were $2.48 \times 10^{3}$ ha, $4.78 \times 10^{3}$ ha, and $1.29 \times 10^{3}$ ha, accounting for $11.67 \%, 22.54 \%$, and $6.08 \%$ of the total converted area of wheat, respectively. The area of barley converted to corn, wheat, and oilseed rape was $0.77 \times 10^{3}$ ha, $7.24 \times 10^{3}$ ha, and $0.77 \times 10^{3}$ ha, accounting for $3.64 \%, 34.12 \%$, and $3.60 \%$ of the total converted area of barley, respectively. The area of oilseed rape converted to corn, wheat, and barley was $6.77 \times 10^{3}$ ha, $0.10 \times 10^{3}$ ha, and $0.21 \times 10^{3}$ ha, accounting for $31.88 \%, 0.49 \%$, and $1.00 \%$ of the total converted area of oilseed rape, respectively.

From 2007 to 2012, most of the other crops were converted to the four main crops distributed throughout the whole of Zhangye City, except for Sunan (Fig. 5). Most wheat was converted from other crops distributed in Ganzhou and Minle, while barley was converted from other crops in Minle and Shandan. Most of the corns converted from other crops were distributed in Ganzhou, Linze, and Gaotai. A small number of increased corns were scattered about in the south of Minle and in Shandan where most of the oilseed rape converted from other crops was distributed. Most of the wheat and barley converted from other crops was widely distributed in Minle and Shandan.

\subsection{Changes in the landscape pattern of crops}

From 2007 to 2012, the MPS of corn and oilseed rape increased from 6.06 ha to 1.89 ha-11.75 ha and 2.34 ha, respectively, showing a tendency for concentrated sowing (Fig. 6a). However, wheat and barley showed a decrease in MPS from 4.73 ha to 5.98 ha-2.73 ha and 1.94 ha, respectively, suggesting a decentralizing tendency in sowing. Among the four main crop types, the MPS was highest for corn, indicating that its sowing was the least fragmented. Finally, the MPS of each crop type ranged from 1.94 ha to 11.75 ha. This indicates it is necessary to choose remote sensing images with either a middle or high spatial resolution to extract crop type in Zhangye because the area of one pixel of the low-resolution remote sensing images was at least 6.25 ha $(250 \mathrm{~m} \times 250 \mathrm{~m})$.

Corn had the greatest LPI among the crops dominating the cultivated land landscape in Zhangye City. Its LPI increased from $2.83 \%$ in 2007 to $3.39 \%$ in 2012 (Fig. 6b). The LPI of oilseed rape also increased from $0.10 \%$ to $0.42 \%$, whereas the LPI of wheat and barley decreased quickly from $1.32 \%$ to $0.67 \%-0.55 \%$ and $0.11 \%$, respectively.

The ED of corn was also the largest among the four major crop types. Thus, in this cultivated landscape cornfields had high connectivity which can serve as an indispensable channel for the energy transfer and material interaction between corn and nearby non-cultivated landscapes (Fig. 6c). From 2007 to 2012, the ED of corn and barley decreased from $33.39 \mathrm{~m} / \mathrm{ha}$ and $11.34 \mathrm{~m} / \mathrm{ha}$ to $32.38 \mathrm{~m} /$ ha and $10.41 \mathrm{~m} / \mathrm{ha}$, respectively, indicating a decrease in connectivity. By contrast, the ED of wheat and oilseed rape increased from $12.88 \mathrm{~m} / \mathrm{ha}$ and $8.98 \mathrm{~m} /$ ha to $17.02 \mathrm{~m} / \mathrm{ha}$ and $10.40 \mathrm{~m} / \mathrm{ha}$, indicating an increase in connectivity.

The CONTAG in the cultivated landscape increased from $57.03 \%$ in 2007 to $56.03 \%$ in 2012 , indicating a decrease in connectivity and an increase in fragmentation of cultivated land (Fig. 6d). Moreover, the SHDI increased from 1.0079 to 1.0363: this means increased fragmentation and diversity of crop sowing in the cultivated landscape.

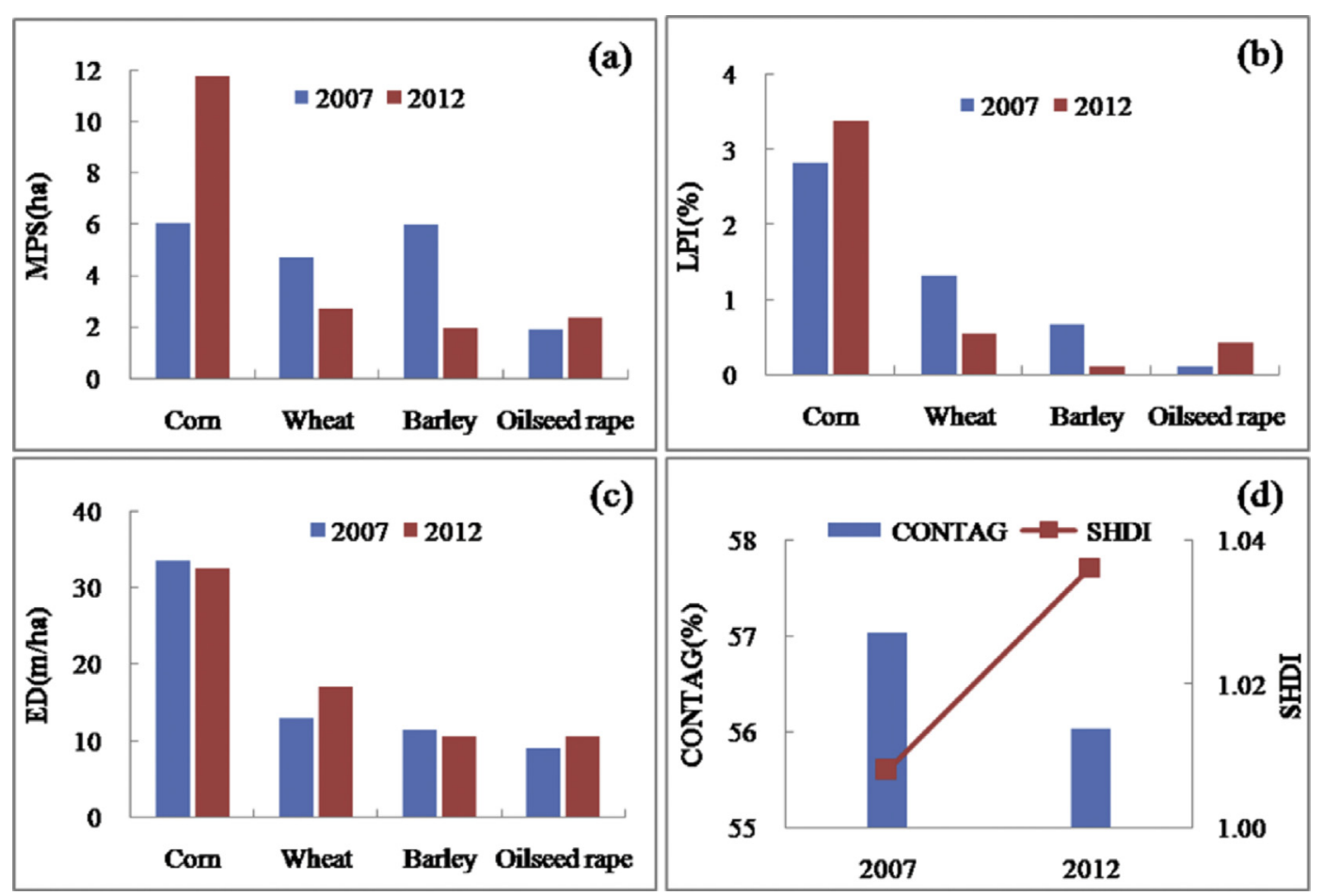

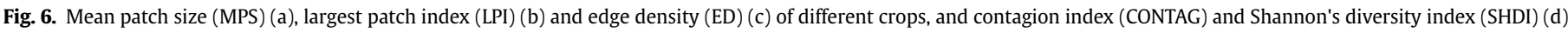
of cultivated land in Zhangye in 2007 and 2012. 


\subsection{Modeling of crop conversion potentials}

After evaluating the changes in crop type from 2007 to 2012, we established four conversion sub-models of corn, wheat, barley, and oilseed rape, respectively, to assess their crop conversion potentials in 2017 based on the Multi-Layer Perceptron (MLP) neural network of the Land Change Modeler (LCM) (Table 6). These sub-models shared the same driver variables i.e. elevation, slope, precipitation, temperature, distance to roads, distance to rivers, and distance to settlement places. The elevation and slope variables were static while the rest of the variables were dynamic. The performance of the sub-models of corn, wheat, barley, and oilseed rape were all robust in that they had accuracies of $79.53 \%, 75.49 \%, 81.52 \%$, and $69.86 \%$, respectively.

According to development trends from 2007 to 2012, the conversion potentials of four main crops in 2017 revealed distinguished spatial heterogeneity, namely due to differences in natural and social resource conditions. The crops most likely to be transferred to corn were primarily distributed in Linze and Gaotai; in contrast, the conversion potentials of corns in Minle and Shandan were low
(Fig. 7a). The water consumption of corn was higher than that of the other three main crops. Both Linze and Gaotai had the most convenient conditions for irrigation water among the counties in Zhangye as the main stream of the Heihe River flowed through each (Fig. 1). Therefore, the conversion potentials of corn in these two counties were greatest. In particular, the conversion potentials of corn in Ganzhou were lower than those in Linze and Gaotai while they were higher than those in Minle and Shandan. However, the accumulated temperature of most areas in high-altitude Minle and Shandan was inappropriate for sowing thermophilic corn. Minle and Shandan are more suited for the sowing of hardy crops, namely wheat, barley, and oilseed rape in 2017 (Fig. 7b-d). The highest conversion potentials of wheat appeared in central Minle and Shandan (Fig. 7b). However, the conversion potentials of wheat in Ganzhou, Linze, and Gaotai were only slightly lower than those in Minle because wheat is essential food in Zhangye City. The crops most likely to be converted into barley are primarily distributed in west Sunan and in the south border area between Ganzhou and Minle (Fig. 7c). By contrast, the areas with low conversion potentials into barley are primarily distributed in the southwest of Minle

Table 6

Sub-models of crop conversion potentials for the Multi-Layer Perceptron (MLP) neural network.

\begin{tabular}{|c|c|c|c|c|}
\hline $\begin{array}{l}\text { Sub- } \\
\text { models }\end{array}$ & Conversion types & Driver variables & Parameters & $\begin{array}{l}\text { Accuracy } \\
\text { rate }\end{array}$ \\
\hline Corn & $\begin{array}{l}\text { From wheat, barley and } \\
\text { oilseed rape to corn }\end{array}$ & $\begin{array}{l}\text { Elevation, slope, precipitation, temperature, distance to roads, distance to } \\
\text { rivers, distance to settlement places }\end{array}$ & $\begin{array}{l}\text { Sample size: } 8589 \text {, learning rate: } 0.015 \% \text {, } \\
\text { iterations: } 10,000\end{array}$ & $79.53 \%$ \\
\hline Wheat & $\begin{array}{l}\text { From corn, barley and oilseed } \\
\text { rape to wheat }\end{array}$ & & $\begin{array}{l}\text { Sample size: } 1159 \text {, learning rate: } 0.030 \% \text {, } \\
\text { iterations: } 10,000\end{array}$ & $75.49 \%$ \\
\hline Barley & $\begin{array}{l}\text { From corn, wheat and oilseed } \\
\text { rape to barley }\end{array}$ & & $\begin{array}{l}\text { Sample size: } 1791 \text {, learning rate: } 0.025 \% \text {, } \\
\text { iterations: } 10,000\end{array}$ & $81.52 \%$ \\
\hline $\begin{array}{l}\text { Oilseed } \\
\text { rape }\end{array}$ & $\begin{array}{l}\text { From corn, wheat and barley to } \\
\text { oilseed rape }\end{array}$ & & $\begin{array}{l}\text { Sample size: } 527 \text {, learning rate: } 0.025 \% \text {, } \\
\text { iterations: } 10,000\end{array}$ & $69.86 \%$ \\
\hline
\end{tabular}

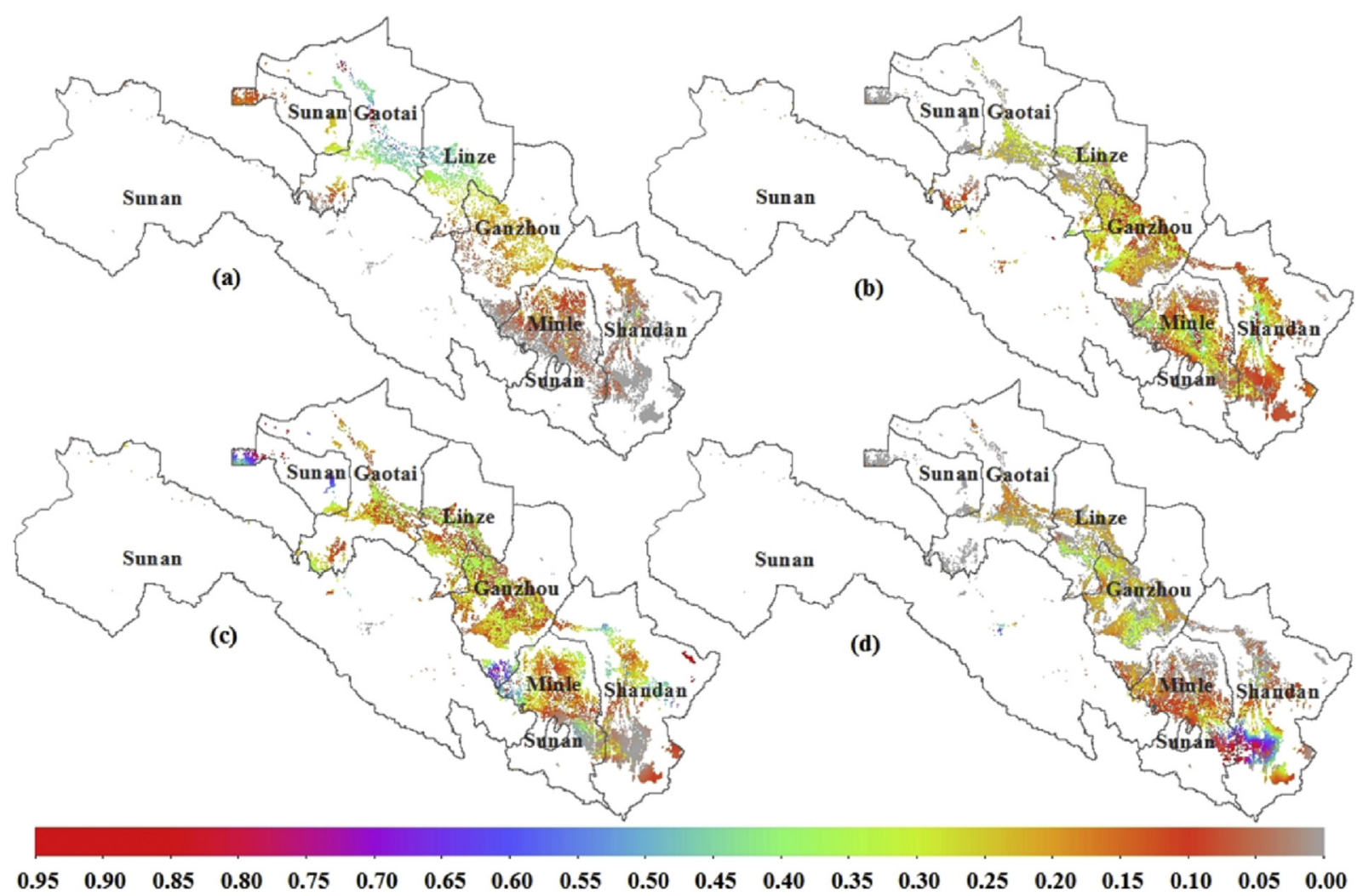

Fig. 7. Conversion potentials of corn (a), wheat (b), barley (c) and oilseed rape (d) in Zhangye in 2017. 
and the southeast of Shandan, where they also have high conversion potentials for oilseed rape.

\section{Discussion}

\subsection{Reasons for the crop type distribution and its changes in Zhangye City}

The crop type distribution and its documented changes were most likely the outcome of farmers' rational decisions about what to sow and reap. Their decision was, in part, also influenced by considerations of agricultural water consumption, global warming, short-term economic benefits, and policy guidance. The uneven distribution of agricultural irrigation water in both space and time underpins the regional differentiation of the four staple crops. Corn, which demands much water, is mainly distributed in Ganzhou, Linze, and Gaotai counties of Zhangye. Conversely, the wheat, barley and oilseed rape are mainly distributed in high-altitude Minle and Shandan counties. Because of their lower water tables, neither Minle nor Shandan are fit for the construction of irrigation systems. Furthermore, the supply of agricultural irrigation water is also unevenly distributed during the year. Most of the water is concentrated in July and August, which does not favor the sowing of autumn crops (corn and oilseed rape) whose water requirements are instead concentrated in July and August. On the contrary, the water requirement of summer crops, such as wheat and barley, are concentrated in May and June when there is a shortage of water. This uneven temporal distribution of available agricultural water leads, not surprisingly, to the increase of autumn crops and the decrease of summer crops to varying degrees.

Global warming has contributed to the expansion of thermophilic corn and the reduction of hardy wheat and barley. Furthermore, global warming has increased the frost-free period and accumulated temperatures, facilitating the expansion of corn to high latitude areas in northwestern Zhangye and high altitude areas in southeastern Zhangye. Unfortunately, global warming has also intensified the water shortage in arid areas of northwestern China (Deng \& Zhao, 2015). The excessive expansion of cultivated land should be curbed soon, and the crop sowing type ought to be reasonably adjusted to alleviate the water shortage risks in Zhangye.

If natural conditions permit, farmers in Zhangye are generally inclined to sow cash crops that return higher economic benefits to them than the grain crops. This has so far led to the significant increase of cash crops planted, such as corn and oilseed rape, and the decrease of grain crops such as wheat and barley. However, such cash crop cultivation will require more labor than that for cultivating grain crops. China is experiencing a fast migration of laborers from rural to urban areas that is being driven by rapid economic development (Song \& Pijanowski, 2014; Song, 2014). This migration undoubtedly leads to labor shortages in rural areas, which in turn constrains the establishment of plantings of laborintensive cash crops in many regions. This labor constraint may, however, eventually assist in reversing the planting losses of grain crops to some degree.

The Chinese government has implemented several policies to encourage the planting of grain crops to guarantee food security. According to the current agriculture subsidy policy in China, grain crops receive a higher subsidy quota than cash crops. Furthermore, this subsidy does not cover all possible cash crops. Compared with the inconsistent prices for cash crops, the prices for grain crops are relative steady due to the protective purchasing price policy, which decreases the risks of planting of grain crops. Moreover, Zhangye remains one of the largest bases of seed corn production in China. Corn plantings have been encouraged by the government, leading to the continuous recent increases of its sowing area.

\subsection{Effects of the changes in crop type distribution}

The changes in crop type distribution in Zhangye City not only improved the economic benefits of crop planting, but they also alleviated the temporal contradictions between the supply and consumption of agricultural irrigation water. First, due to the rapid development of the economy and of urbanization, the opportunity cost of crop plantings has gradually increased. The increased sowing area of corn and oilseed rape should help farmers in Zhangye acquire more economic benefits. Second, the water requirement of summer crops is not well matched to the temporal irrigation supply in Zhangye. A decrease in sowing areas of wheat and barley can help alleviate these contradicting forces. Lastly, the fragmentation and diversity of the cultivated land landscape in Zhangye City has increased due to the changes in crop type distributions.

However, many of the increased sowing areas of crops arose from the expansion of cultivated land in Zhangye City, thereby intensifying the water shortage in the Heihe River Basin. In addition, although crop conversions from wheat and barley to corn solved the uneven temporal distribution of agricultural water to some degree, they increased water consumption because of the high water demand of corn. While this conversion may likely improve the economic benefits of crop plantings and alleviate the temporal pressures of agricultural water supply and consumption, the overall agricultural water consumption in Zhangye City has in fact increased. The increase of water consumption in agriculture could thus displace water consumption in non-agriculture sectors, generating negative feedback influences on regional sustainable development. Accordingly, to resolve the conflict between agricultural water supply and demand, to improve water using efficiency, and to promote the sustainable development of the regional ecosystem (Deng et al., 2006; Deng, Shi, Zhang, Shi, \& Yin, 2015, Deng, Huang, Rozelle, Zhang, \& Li, 2015), it is indispensable to slow the excessive expansion of cultivated land, plant more watersaving crops, and adjust the crop sowing schemes in Zhangye as soon as possible.

\subsection{Uncertainty of the research}

The cultivated land in Zhangye is fragmented and has an average land plot size of 1 ha due to the pattern of complex crop planting found there. According to the landscape pattern analysis, the mean patch size of each crop was thus small. This indicates that it is infeasible to extract crop type distributions in Zhangye using high temporal resolution images at low spatial resolution. Thus, TM/ ETM+ images that use a middle spatial resolution of $30 \mathrm{~m}$ can effectively reduce the classification error caused by mixed pixels. The crop type differences in various phenophases can be captured by virtue of the 16-day temporal resolution. However, the influence of clouds on the TM/ETM+ images hindered the ability to obtain continuous time-series data for an interval of 16 days. If the clouds could somehow be effectively removed, the temporal resolution of images would be enhanced, thus improving the classification accuracy. Nevertheless, although much research has been performed on cloud effect removal of TM/ETM+ images and such effects have been identified for small-scale experimental areas, an applicable automatic cloud removal method over large-scale areas remains elusive (Goodwin, Collett, Denham, Flood, \& Tindall, 2013; Zhu \& Woodcock, 2012).

Due to the differences in natural conditions and sowing habits, the growing conditions of the same crop inevitably varied with location. This resulted in the phenomenon of "the same crop with various spectra", which affected the classification accuracy to some 
degree. However, in this study several aspects reduced the influence of this phenomenon. First, the boundaries of cultivated land as obtained by visual interpretation were used to mask the images, thus avoiding the effects of other vegetation on our crop classification. Second, the stratified pure pixel sampling to select classification samples avoided the mixed pixels in each crop type. Third, the samples with various growth conditions were selected to cover Zhangye entirely. This approach to sample selection reduced the effects of the same crop with various spectra on classification. Lastly, the threshold values of key time-windows of NDVWI were set according to the NDVWI time-series curves of all representative crop classification samples. In this way, the potential influence of extremely good- or bad-growing crops on the classification was eliminated.

Crop type distribution of Zhangye in 2012 was obtained from crop classification samples in 2012. Lacking crop classification samples in 2007, we had to establish the classification rules of 2007 according to the NDVWI time-series curves of 2012. This recourse could have slightly influenced the classification accuracy of 2007 due to any crop growth differences between 2007 and 2012. Indeed, there exist several approaches to historical sampling, such as visual sampling based on historical high spatial resolution remote images. However, this was not applicable in this study because of the difficulty in visually interpreting crop classification.

Rigorously assessing crop conversion potentials is important for predicting changes in crop types. We modeled conversion potentials of corn, wheat, barley, and oilseed rape based on the MultiLayer Perceptron (MLP) neural network using sub-models. In so doing, we selected many topographic, meteorological, and socioeconomic variables. These variables can either directly or indirectly influence crop growing conditions and yields. However, because of the lack of accessible data at present, several variables that can further affect crop type conversion, such as groundwater availability, human population, and distance to irrigation channels, were not considered in the model.

\section{Conclusion}

In this study, we classified and analyzed the crop type distribution of Zhangye from 2007 to 2012, and then modeled the crop conversion potentials in 2017. TM/ETM+ images with an intermediate spatial resolution of $30 \mathrm{~m}$ and 16-day temporal resolution were used successfully to extract the crop type distribution. It was found that in the areas with fragmented cultivated land and complex planting patterns, Multi-temporal NDVWI serves as a robust index to discern crop type distribution, and the classification accuracy of this approach reached $89.38 \%$.

The sowing of corn and oilseed rape has increased by $39.21 \times 10^{3}$ ha and $5.99 \times 10^{3}$ ha while wheat and barley has decreased by $3.61 \times 10^{3}$ ha and $9.14 \times 10^{3}$ ha from 2007 to 2012 , respectively. Corn is mainly planted in the Ganzhou, Linze, and Gaotai counties of Zhangye, while wheat, barley, and oilseed rape are mainly planted in Minle and Shandan counties. The planting of corn and oilseed rape tended towards intensification whereas that of wheat and barley tended towards a scattering or pattern of decentralization. The conversion potentials of corn, wheat, barley, and oilseed rape were unalike in 2017, peaking for corn in Linze and Gaotai counties, and peaking for barley and oilseed rape in Minle and Shandan counties.

Human productive activities on crop type distribution led to an increasing fragmentation and diversity of the landscape pattern of cultivated land in Zhangye. The changes in crop type distribution were beneficial for improving economic benefits and alleviating the temporal constraints in the supply and demand for agricultural water. Taken together, however, the changes in crop sowing increased the overall consumption of agricultural water in Zhangye, which was driven by the expansion of corn cultivation that demands the most water resources among grain crops.

\section{Acknowledgement}

The research was supported by the National Natural Science Foundation of China (Gran Nos. 91325302, 41671177 and 41501192).

\section{References}

Atzberger, C., \& Rembold, F. (2013). Mapping the spatial distribution of winter crops at sub-pixel level using AVHRR NDVI time series and neural nets. Remote Sensing, 5(3), 1335-1354.

Basche, A. D., Archontoulis, S. V., Kaspar, T. C., Dan, B. J., Parkin, T. B., \& Miguez, F. E. (2016). Simulating long-term impacts of cover crops and climate change on crop production and environmental outcomes in the Midwestern United States. Agriculture Ecosystems \& Environment, 218, 95-106.

Becker-Reshef, I. Vermote, E. Lindeman, M. \& Justice, C. (2010). A generalized regression-based model for forecasting winter wheat yields in Kansas and Ukraine using MODIS data. Remote Sensing of Environment, 114(6), 1312-1323.

Boryan, C. Yang, Z. W. Mueller, R. \& Craig, M. (2011). Monitoring US agriculture: The US Department of Agriculture, National Agricultural Statistics Service, Cropland data layer program. Geocarto International, 26(5), 341-358.

Bouman, B. A. M. (1992). Linking physical remote-sensing models with crop growth simulation-models, applied for sugar-beet. International Journal of Remote Sensing, 13(14), 2565-2581.

Camps-Valls, G., Gomez-Chova, L., Calpe-Maravilla, J., Soria-Olivas, E., MartinGuerrero, J. D., \& Moreno, J. (2003). Support vector machines for crop classification using hyperspectral date. Pattern Recognition and Image Analysis, Proceedings, 2652, 134-141.

Castillejo-Gonzalez, I. L., Lopez-Granados, F., Garcia-Ferrer, A., Pena-Barragan, J. M., Jurado-Exposito, M. de la Orden, M. S., et al. (2009). Object- and pixel-based analysis for mapping crops and their agro-environmental associated measures using QuickBird imagery. Computers and Electronics in Agriculture, 68(2), 207-215.

Chavez, P. S., Berlin, G. L., \& Sowers, L. B. (1984). Statistical method for selecting landsat mss ratios 147. Journal of Applied Photographic Engineering, 8(1), 23-30.

Chen, C. F., Son, N. T., Chang, L. Y., \& Chen, C. C. (2011). Monitoring of soil moisture variability in relation to rice cropping systems in the Vietnamese Mekong Delta using MODIS data. Applied Geography, 31(2), 463-475.

Chen, L. D., Wang, J., Fu, B. J., \& Qiu, Y. (2001). Land-use change in a small catchment of northern Loess Plateau, China. Agriculture Ecosystems \& Environment, 86(2), 163-172.

Clevers, J. G. P. W., \& vanLeeuwen, H. J. C. (1996). Combined use of optical and microwave remote sensing data for crop growth monitoring. Remote Sensing of Environment, 56(1), 42-51.

Congalton, R. G. (1991). A review of assessing the accuracy of classifications of remotely sensed data. Remote Sensing of Environment, 37(1), 35-46.

Conrad, C., Fritsch, S., Zeidler, J., Rucker, G., \& Dech, S. (2010). Per-field irrigated crop classification in Arid Central Asia using SPOT and ASTER data. Remote Sensing, 2(4), 1035-1056.

Deng, X. Z., Huang, J. K., Rozelle, S., \& Uchida, E. (2006). Cultivated land conversion and potential agricultural productivity in China. Land Use Policy, 23(4), $372-384$

Deng, X. Z., Huang, J. K., Rozelle, S., Zhang, J. P., \& Li, Z. H. (2015). Impact of urbanization on cultivated land changes in China. Land Use Policy, 45, 1-7.

Deng, X., Shi, Q., Zhang, Q., Shi, C., \& Yin, F. (2015). Impacts of land use and land cover changes on surface energy and water balance in the Heihe River Basin of China, 2000-2010. Physics and Chemistry of the Earth, Parts A/B/C, 79-82, 2-10.

Deng, X., \& Zhao, C. (2015). Identification of water scarcity and providing solutions for adapting to climate changes in the Heihe River Basin of China. Advances in Meteorology, 2015, 1-13.

The Department of Crop Production in the Ministry of Agriculture of China (DCPMOAC). (2012). Available at: http://www.zzys.moa.gov.cn/. Accessed August 15, 2014

Duro, D. C., Franklin, S. E., \& Dube, M. G. (2012). A comparison of pixel-based and object-based image analysis with selected machine learning algorithms for the classification of agricultural landscapes using SPOT-5 HRG imagery. Remote Sensing of Environment, 118, 259-272.

Friedl, M. A., \& Brodley, C. E. (1997). Decision tree classification of land cover from remotely sensed data. Remote Sensing of Environment, 61(3), 399-409.

Gao, B. C. (1997). NDWI-a normalized difference water index for remote sensing of vegetation liquid water from space. Remote Sensing of Environment, 58(3), 257-266.

The Geospatial Data Cloud of China (GDCC). (2012). Available at: http://www. gscloud.cn/. Accessed August 10, 2014.

Goodwin, N. R., Collett, L. J., Denham, R. J., Flood, N., \& Tindall, D. (2013). Cloud and cloud shadow screening across Queensland, Australia: An automated method for Landsat TM/ETM plus time series. Remote Sensing of Environment, 134, 50-65. 
Gu, J. Y., Congalton, R. G., \& Pan, Y. Z. (2015). The impact of positional errors on soft classification accuracy assessment: A simulation analysis. Remote Sensing, 7(1), 579-599.

Houston, A. G., \& Hall, F. G. (1984). Use of satellite data in agricultural surveys. Communications In Statistics-Theory and Methods, 13(23), 2857-2880.

Huete, A., Didan, K., Miura, T., Rodriguez, E. P., Gao, X., \& Ferreira, L. G. (2002). Overview of the radiometric and biophysical performance of the modis vegetation indices. Remote Sensing of Environment, 83(1-2), 195-213.

Jain, M., Mondal, P., DeFries, R. S., Small, C., \& Galford, G. L. (2013). Mapping cropping intensity of smallholder farms: A comparison of methods using multiple sensors. Remote Sensing of Environment, 134, 210-223.

Johnson, L. F., \& Trout, T. J. (2012). Satellite NDVI assisted monitoring of vegetable crop evapotranspiration in California's San Joaquin valley. Remote Sensing, 4(2), 439-455.

Li, Z., \& Fox, J. M. (2012). Mapping rubber tree growth in mainland Southeast Asia using time-series MODIS 250 m NDVI and statistical data. Applied Geography, 32(2), 420-432.

Lin, G. C. S., \& Ho, S. P. S. (2003). China's land resources and land-use change: Insights from the 1996 land survey. Land Use Policy, 20(2), 87-107.

Liu, X. L., \& Bo, Y. C. (2015). Object-based crop species classification based on the combination of airborne hyperspectral images and LiDAR data. Remote Sensing, 7(1), 922-950.

Liu, M. L., \& Tian, H. Q. (2010). China's land cover and land use change from 1700 to 2005: Estimations from high-resolution satellite data and historical archives. Global Biogeochemical Cycles, 24.

Liu, M. L., Tian, H. Q., Chen, G. S., Ren, W., Zhang, C., \& Liu, J. Y. (2008). Effects of landuse and land-cover change on evapotranspiration and water yield in China during 1900-2000. Journal of the American Water Resources Association, 44(5), 1193-1207.

Lobell, D. B. (2013). The use of satellite data for crop yield gap analysis. Field Crops Research, 143, 56-64.

Lobell, D. B., \& Asner, G. P. (2004). Cropland distributions from temporal unmixing of MODIS data. Remote Sensing of Environment, 93(3), 412-422.

Macdonald, R. B., \& Hall, F. G. (1980). Global crop forecasting. Science, 208(4445), 670-679.

Mahesh, S., Jayas, D. S., Paliwal, J., \& White, N. D. G. (2015). Hyperspectral imaging to classify and monitor quality of agricultural materials. Journal of Stored Products Research, 61, 17-26.

Mcgarigal, K., \& Marks, B. J. (1995). FRAGSTATS: Spatial pattern analysis program for quantifying landscape structure. Portland, OR: U.S. Department of Agriculture, Forest Service, Pacific Northwest Research Station.

The Meteorological Data Sharing Service System of China (MDSSSC). (2012). Available at: http://data.cma.cn/. Accessed July 12, 2015

Nidamanuri, R. R., \& Zbell, B. (2011). Transferring spectral libraries of canopy reflectance for crop classification using hyperspectral remote sensing data. Biosystems Engineering, 110(3), 231-246.

Pal, M., \& Mather, P. M. (2003). An assessment of the effectiveness of decision tree methods for land cover classification. Remote Sensing of Environment, 86(4), 554-565.

Patel, N. R., Bhattacharjee, B., Mohammed, A. J., Tanupriya, B., \& Saha, S. K. (2006). Remote sensing of regional yield assessment of wheat in Haryana, India. International Journal of Remote Sensing, 27(19), 4071-4090.

Perdigao, A., Vossen, P., \& Gallego, J. (1997). The MARS project: The European approach adaptable to national needs. New Tools for Agriculture and Forestry Statistics, 63-78.

Pinter, P. J., Ritchie, J. C., Hatfield, J. L., \& Hart, G. F. (2003). The agricultural research service's remote sensing program: An example of interagency collaboration. Photogrammetric Engineering and Remote Sensing, 69(6), 615-618.

Sangermano, F., Eastman, J. R., \& Zhu, H. (2010). Similarity weighted instance-based learning for the generation of transition potentials in land use change modeling. Transactions in Gis, 14(5), 569-580.

Song, W. (2014). Decoupling cultivated land loss by construction occupation from economic growth in Beijing. Habitat International, 43, 198-205.

Song, W., Chen, B., \& Zhang, Y. (2013). Land-use change and socio-economic driving forces of rural settlement in China from 1996 to 2005. Chinese Geographical Science, 24(5), 511-524.

Song, W., Deng, X. Z., Liu, B., Li, Z. H., \& Jin, G. (2015). Impacts of grain-for-green and grain-for-blue policies on valued ecosystem services in Shandong Province, China. Advances in Meteorology, 2015.

Song, W., Deng, X., Yuan, Y., Wang, Z., \& Li, Z. (2015). Impacts of land-use change on valued ecosystem service in rapidly urbanized North China Plain. Ecological Modelling, 318, 245-253.

Song, W., \& Liu, M. L. (2014). Assessment of decoupling between rural settlement area and rural population in China. Land Use Policy, 39, 331-341.

Song, W., \& Pijanowski, B. C. (2014). The effects of China's cultivated land balance program on potential land productivity at a national scale. Applied Geography, $46,158-170$.

Stehman, S. V., \& Milliken, J. A. (2007). Estimating the effect of crop classification error on evapotranspiration derived from remote sensing in the lower Colorado
River Basin, USA. Remote Sensing of Environment, 106(2), 217-227.

Sun, H. S., Xu, A. G., Lin, H., Zhang, L. P. \& Mei, Y. (2012). Winter wheat mapping using temporal signatures of MODIS vegetation index data. International Journal of Remote Sensing, 33(16), 5026-5042.

Su, S. L., Yang, C. X., Hu, Y. N., Luo, F. H., \& Wang, Y. P. (2014). Progressive landscape fragmentation in relation to cash crop cultivation. Applied Geography, 53, 20-31.

Tayyebi, A., \& Pijanowski, B. C. (2014). Modeling multiple land use changes using ANN, CART and MARS: Comparing tradeoffs in goodness of fit and explanatory power of data mining tools. International Journal of Applied Earth Observation and Geoinformation, 28, 102-116.

Tayyebi, A., Pijanowski, B. C., Linderman, M., \& Gratton, C. (2014). Comparing three global parametric and local non-parametric models to simulate land use change in diverse areas of the world. Environmental Modelling \& Software, 59, 202-221.

The Data Management Center of the Heihe River Project of China (DMCHRPC) (2012). Heihe Watershed Allied Telemetry Experimental Research (HiWATER): Land cover Map of Heihe River Basin dataset. http://dx.doi.org/10.3972/hiwater.155.2014.db. Available at: http://www.heihedata.org/.

Tong, C. L., Hall, C. A. S., \& Wang, H. Q. (2003). Land use change in rice, wheat and maize production in China (1961-1998). Agriculture Ecosystems \& Environment, $95(2-3), 523-536$

Torres-Sánchez, J., López-Granados, F., \& Peña, J. M. (2015). An automatic objectbased method for optimal thresholding in UAV images: Application for vegetation detection in herbaceous crops. Computers and Electronics in Agriculture, $114,43-52$.

The United States Geological Survey (USGS). (2007). Available at: http://glovis.usgs gov/. Accessed September 25, 2014

The United States Geological Survey (USGS). (2012). Available at: http://glovis.usgs. gov/. Accessed September 25, 2014.

Verbeiren, S., Eerens, H., Piccard, I., Bauwens, I., \& Van Orshoven, J. (2008). Sub-pixel classification of SPOT-VEGETATION time series for the assessment of regional crop areas in Belgium. International Journal of Applied Earth Observation and Geoinformation, 10(4), 486-497.

Verburg, P. H., Chen, Y. Q., \& Veldkamp, T. A. (2000). Spatial explorations of land use change and grain production in China. Agriculture Ecosystems \& Environment, $82(1-3), 333-354$

Wan, L. H., Zhang, Y. W., Zhang, X. Y., Qi, S. Q., \& Na, X. D. (2015). Comparison of land use/land cover change and landscape patterns in Honghe national nature reserve and the surrounding Jiansanjiang Region, China. Ecological Indicators, 51, 205-214.

Whitcraft, A. K., Becker-Reshef, I., \& Justice, C. O. (2015). A framework for defining spatially explicit earth observation requirements for a Global Agricultural Monitoring Initiative (GEOGLAM). Remote Sensing, 7(2), 1461-1481.

Wu, B. F., \& Li, Q. Z. (2012). Crop planting and type proportion method for crop acreage estimation of complex agricultural landscapes. International Journal of Applied Earth Observation and Geoinformation, 16, 101-112.

Xu, S. W., Wu, J. Z., Song, W., Li, Z. Q., Li, Z. M., \& Kong, F. T. (2013). Spatial-tempora changes in grain production, consumption and driving mechanism in China. Journal of Integrative Agriculture, 12(2), 374-385.

Xu, G., Zhang, H. F., Chen, B. Z., Zhang, H. R., Innes, J. L., Wang, G. Y., et al. (2014) Changes in vegetation growth dynamics and relations with climate over China's landmass from 1982 to 2011. Remote Sensing, 6(4), 3263-3283.

Yang, Y. Z., Feng, Z. M., Huang, H. Q., \& Lin, Y. M. (2008). Climate-induced changes in crop water balance during 1960-2001 in Northwest China. Agriculture Ecosystems \& Environment, 127(1-2), 107-118.

Ye, Q., Yang, X., Dai, S., Chen, G., Li, Y., \& Zhang, C. (2015). Effects of climate change on suitable rice cropping areas, cropping systems and crop water requirements in southern China. Agricultural Water Management, 159, 35-44.

You, X. Z, Meng J. H., Zhang, M., \& Dong, T. F. (2013). Remote sensing based detection of crop phenology for agricultural zones in China using a new threshold method. Remote Sensing, 5(7), 3190-3211.

You, L. Z., Spoor, M., Ulimwengu, J., \& Zhang, S. M. (2011). Land use change and environmental stress of wheat, rice and corn production in China. China Economic Review, 22(4), 461-473.

Zhang, S. W., Lei, Y. P., Wang, L. P., Li, H. J., \& Zhao, H. B. (2011). Crop classification using MODIS NDVI data denoised by wavelet: A case study in Hebei plain, China. Chinese Geographical Science, 21(3), 322-333.

Zhang, G. L., Xiao, X. M., Dong, J. W., Kou, W. L., Jin, C., Qin, Y. W., et al. (2015) Mapping paddy rice planting areas through time series analysis of MODIS land surface temperature and vegetation index data. Isprs Journal of Photogrammetry and Remote Sensing, 106, 157-171.

Zhong, B., Ma, P., Nie, A. H., Yang, A. X., Yao, Y. J., Lu, W. B., et al. (2014). Land cover mapping using time series HJ-1/CCD data. Science China-Earth Sciences, 57(8), $1790-1799$

Zhou, Q., Wu, F., \& Zhang, Q. (2015). Is irrigation water price an effective leverage for water management? An empirical study in the middle reaches of the Heihe River Basin. Physics and Chemistry of the Earth, 89-90, 25-32.

Zhu, Z., \& Woodcock, C. E. (2012). Object-based cloud and cloud shadow detection in Landsat imagery. Remote Sensing of Environment, 118, 83-94. 